\title{
Ultrahigh field magnetic resonance imaging and spectroscopy
}

\author{
Kâmil Uğurbil*, Gregor Adriany, Peter Andersen, Wei Chen, Michael Garwood, \\ Rolf Gruetter, Pierre-Gil Henry, Seong-Gi Kim, Haiying Lieu, Ivan Tkac, Tommy Vaughan, \\ Pierre-Francoise Van De Moortele, Essa Yacoub, Xiao-Hong Zhu
}

Center for Magnetic Resonance Research, University of Minnesota Medical School, Minneapolis, MN 55455, USA

Received 15 August 2003; received in revised form 22 August 2003; accepted 23 August 2003

\section{Introduction}

In our laboratory, the effort to pursue high magnetic fields has been intricately tied to our interest in developing methods for the acquisition of physiological and biochemical information noninvasively using the nuclear spins of the water molecules and metabolites in the human body. In this effort, a relatively recent and unique accomplishment has been the introduction of the ability to map human brain function noninvasively. The concurrent and independent work performed at the University of Minnesota, Center for Magnetic Resonance Research [1] and at MGH [2], was, in our case, conducted at 4 Tesla. It was one of the first experiments performed at 4 Tesla in our laboratory. Today, functional images with subcentimeter resolution of the entire human brain can be generated in single subjects and in data acquisition times of several minutes using 1.5 Tesla MRI scanners that are often employed in hospitals for clinical diagnosis. However, there have been advantages in using significantly higher magnetic fields such as 4 Tesla, and recently 7 Tesla in humans, and 9.4 Tesla in animal models. Similarly, over the last two-and-a-half decades, spectroscopy studies in intact cells have proven to be rich in biochemical information. However, the most useful of these studies were performed in isolated cells or perfused tissues. Only recently, they were extended to small animal models using high magnetic fields. In human applications, spectroscopy efforts pursued at the commonly available magnetic field of 1.5 Tesla were in general unable to produce data comparable in information to the high field perfused organ or animal model data. This has changed with the availability of ultrahigh magnetic fields for human applications. While the use of very high magnetic fields such as 7 Tesla in human studies is still in its infancy, the data

\footnotetext{
* Corresponding author.

E-mail address: kamil@cmrr.umn.edu (K. Ugurbil).
}

gathered to date suggest that there are significant gains for spectroscopy studies in general and some of these accomplishments relevant to high magnetic fields are reviewed in article.

\section{Imaging using the hydrogen nucleus}

\subsection{Signal-to-noise ratio (SNR)}

In all NMR experiments, especially in in vivo applications, gains in SNR are the key to extending the applications of this phenomenon to new frontiers in research. SNR gains can be achieved in going to higher fields. SNR, however, becomes rather complex when high magnetic fields (hence high frequencies) are considered with lossy biologic samples such as the human body and the human head. The relationship between SNR and resonance frequency, $\omega$, or equivalently field strength has been examined for biologic samples in numerous studies [3-9], predicting increases with field strength. At high frequencies such as $170 \mathrm{MHz}$ $\left({ }^{1} \mathrm{H}\right.$ frequency for 4 Tesla) and above, SNR must be considered as a function of location within a sample and for particular sample geometries.

Field dependence of SNR was experimentally examined by our group in the human head, initially comparing 0.5 , 1.5, 4 Tesla $(\sim 21,64,170 \mathrm{MHz}$, respectively), using a surface coil, documenting that SNR for the ${ }^{1} \mathrm{H}$ nucleus increased at least linearly at the higher frequencies [10]. More recently, with the availability of a 7 Tesla human system in our laboratory, we examined and compared the $\mathrm{B}_{1}$ field profile and SNR in the human head for 4 and 7 Tesla when using a TEM "volume" head coil [11]. It was expected that a coil with a uniform $\mathrm{B}_{1}$ field profile when empty will nonetheless lead to a highly nonuniform $\mathrm{B}_{1}$, SNR, and power deposition over the human head and brain. The $\mathrm{B}_{1}$ distribution was mapped over the human head using mag- 


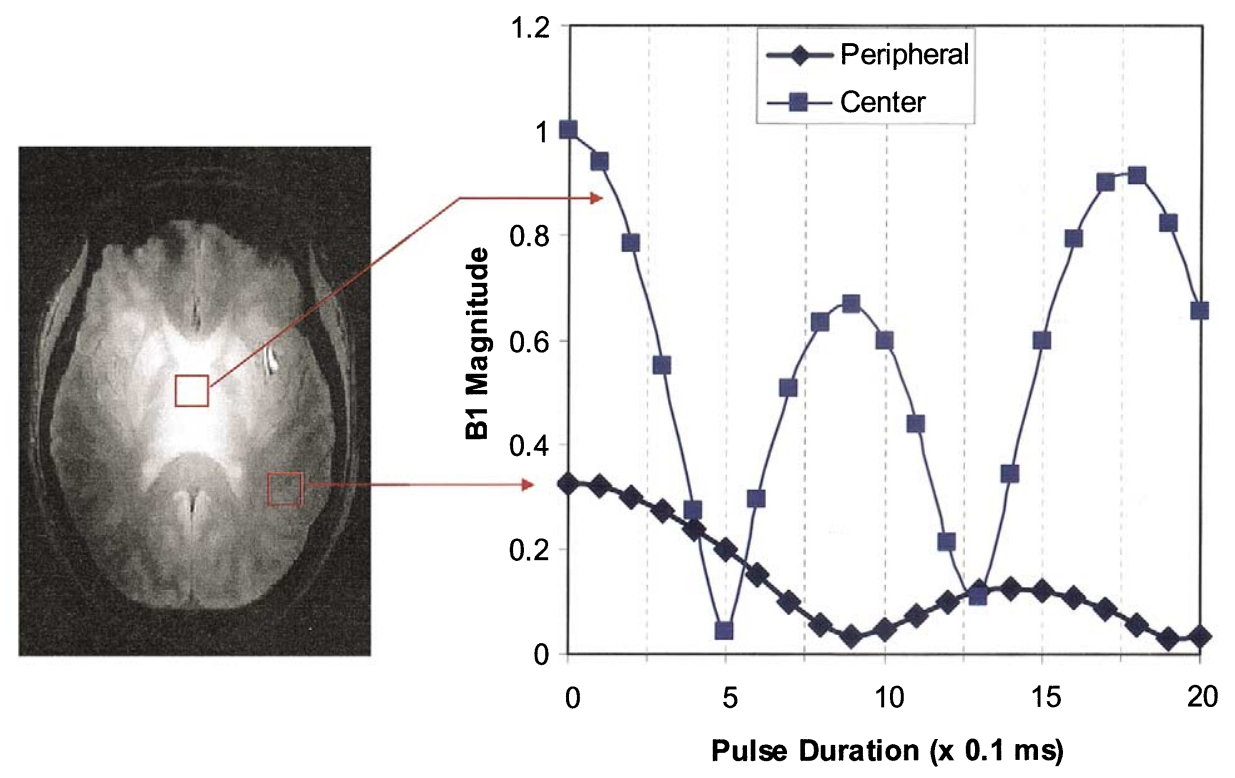

Fig. 1. A, Images of a transverse slice through the human head at 7 Tesla, obtained with magnetization preparation to encode $\mathrm{B}_{1}$ magnitude as $\left\{\right.$ cos $\left(\tau \gamma \mathrm{B}_{1}\right\}$ "turboFlash" (center-out k-space sampling, TR/TE $=4.2 \mathrm{~ms} / 2.5 \mathrm{~ms}$, slice thickness $=5 \mathrm{~mm}$, flip angle $=10^{\circ}$ at the slice center, matrix size $=128 \times 64$ ). The different images correspond to different $\tau ; \mathrm{B}_{1}$ magnitude was kept constant. $\mathrm{B}$, The signal (magnitude) oscillation frequency plotted for two regions of interest in the middle and the periphery of the brain, from the data shown in Fig. 1A. Oscillation frequency is equal to $\gamma B_{1}$ indicating that the $B_{1}$ is substantially higher in the center of the brain. From reference [11].

netization preparation followed by ultrafast imaging ("turboFlash"). Magnetization preparation was accomplished with a variable-duration hard (square) pulse followed by rapid gradient spoiling to eliminate transverse magnetization. The resultant longitudinal magnetization is directly proportional to $\left\{\cos \left(\tau \gamma \mathrm{B}_{1}\right)\right\}$ where $\tau$ and $\gamma$ are the pulse duration and gyromagnetic ratio, respectively. The results demonstrated that the signal intensity oscillates with higher frequency in the brain center than in the periphery at both field strengths but much more so at 7 Tesla (Fig. 1). At 4 T, the $\mathrm{B}_{1}$ strength in the brain periphery was down $23 \%$ from the center value. At $7 \mathrm{~T}$, the peripheral $\mathrm{B}_{1}$ was $42 \%$ lower than the central $B_{1}$. The nonuniform $B_{1}$ profiles obtained experimentally were both expected and predicted by the Maxwell models of the human head loaded TEM coil [11].

Using virtually fully relaxed images when the center of the brain was set to experience a $90^{\circ}$ pulse (thus, by necessity the periphery undergoes a less than $90^{\circ}$ rotation), the SNR scaled more than linearly with field magnitude in the center of the brain, and less than linearly in the periphery. When averaged over the entire slice, SNR at $7 \mathrm{~T}$ increased over $4 \mathrm{~T}$ by 1.6 fold without considering a difference in the gain of the $7 \mathrm{~T}$ and $4 \mathrm{~T}$ coils, and 1.76 times when corrected for the gain difference. Thus, the average SNR for the slice increased linearly. However, the increase was not spatially uniform.

The SNR increases measured in going from 4 to $7 \mathrm{~T}$, were for conditions of same acquisition bandwidth and full relaxation. Such acquisition conditions may be quite appropriate for some imaging applications. If signal averaging is necessary with repetitions that do not permit full relaxation, then, SNR gains at the higher magnetic field will diminish due to the longer $T_{1}$ for some nuclei, such as protons, at the higher magnetic field. Similarly, under many conditions the bandwidth needs to be higher at the higher field strength. For example, in echo planar imaging (EPI), in order to overcome the deleterious effects of increasing $\mathrm{B}_{\mathrm{O}}$ inhomogeneities (and consequently shorter $\mathrm{T}_{2}{ }^{*}$ ), the k-space coverage must be faster. This may be accomplished by scaling the bandwidth with the field magnitude as well, in which case the SNR gain is reduced to square root of the magnetic field ratio. However, solutions to this problem exists in some cases, for example, using restricted field-of-view (FOV) when possible [12-14] or using parallel imaging to reduce the phase encoding steps and thus cutting k-space coverage time.

\subsection{Anatomic imaging}

Prior to the introduction of 4 Tesla systems in academic laboratories, the expectation was that the contrast in anatomic images would decrease due to converging $T_{1}$ values, and would be dominated by the inhomogeneities in signal intensity due to nonuniform $B_{1}$. While the $T_{1}$ values have gotten longer indeed $[15,16]$, they have not converged. In addition, the signal intensity variations expected due to $B_{1}$ inhomogeneities have been suppressed either by insensitivity to $B_{1}$ in the acquisition $[17,18]$ or by postprocessing strategies [11]. Consequently, excellent anatomic imaging has been feasible at magnetic fields of 4 to 8 Tesla in the human brain (e.g, [11,17-25]). Fig. 2 displays an example of a $\mathrm{T}_{1}$-weighted image acquired with $0.8 \times 0.8 \times 1.25$ $\mathrm{mm}^{3}$ spatial resolution and total acquisition time of $5 \mathrm{~min}$ at 7 Tesla, using a volume coil for transmit and receive. 


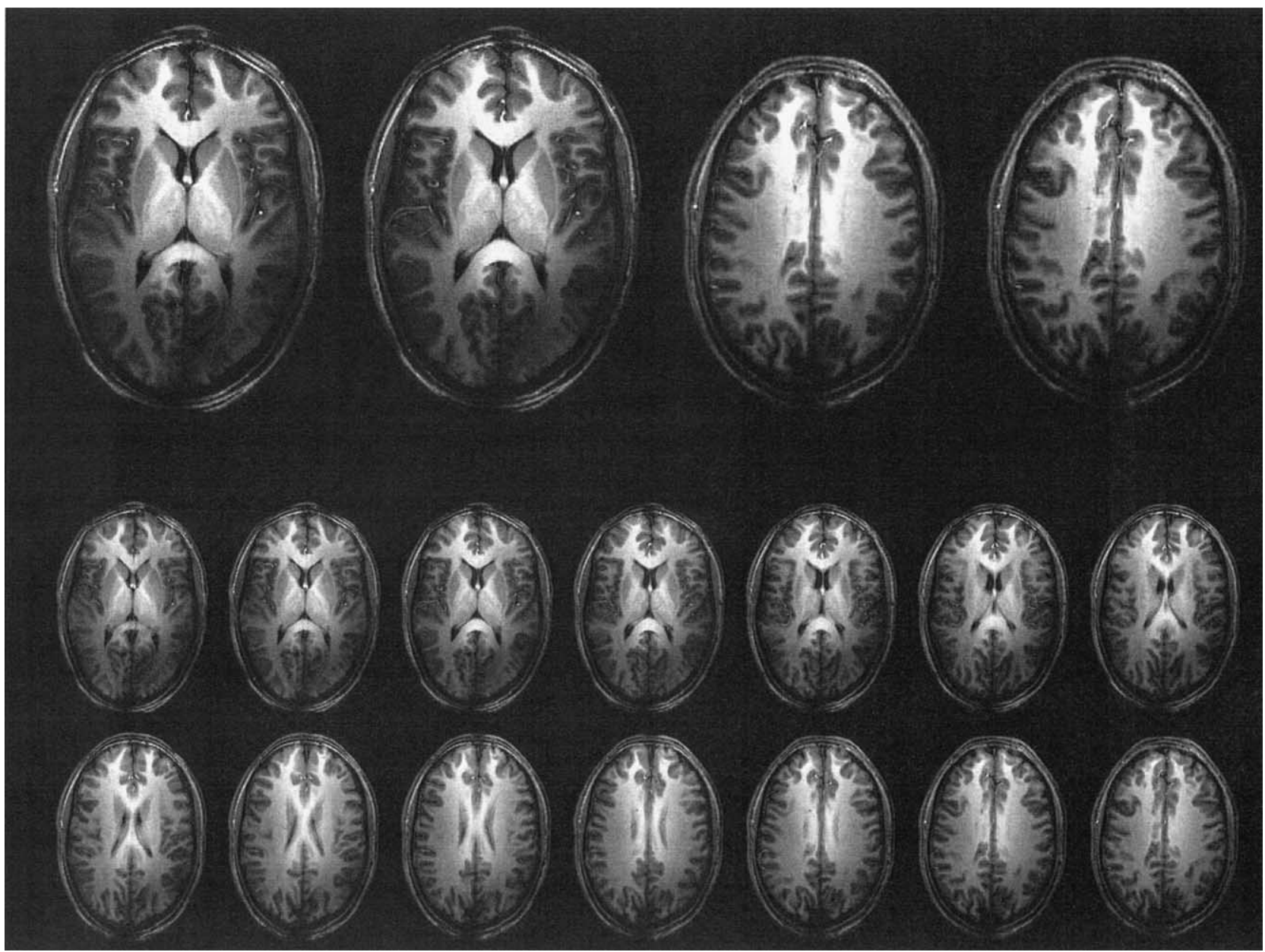

Fig. 2. High resolution ${ }^{1} \mathrm{H}$ image of human brain $\left(0.8 \times 0.8 \times 1.25 \mathrm{~mm}^{3}\right)$ obtained with 3-D acquisition in 5 min. Supplied by Haiying Liu, University of Minnesota.

Improvements on this are expected by the use of multiple coil arrays.

\subsection{Functional imaging}

In the armamentarium of techniques used for investigating brain function, functional magnetic resonance imaging (fMRI) has come to play a dominant role in both human and animal model studies. The most commonly used fMRI approach was introduced in $1992[1,2,26]$ and is based on imaging regional deoxyhemoglobin alterations that accompany changes in neuronal activity. This contrast mechanism, referred to as blood oxygen level-dependent (BOLD) contrast, originates from the intravoxel magnetic field inhomogeneity induced by paramagnetic deoxyhemoglobin sequestered in red blood cells, which in turn are compartmentalized within the blood vessels. Magnetic susceptibility differences between the deoxyhemoglobin-containing compartments versus the surrounding space devoid of this strongly paramagnetic molecule generate magnetic field gradients across and near the boundaries of these compartments. Therefore, signal intensities in magnetic resonance images sensitized to BOLD contrast are altered if the regional deoxyhemoglobin content is perturbed. This occurs in the brain because of the spatially specific metabolic and hemodynamic response to enhanced neuronal activity; it has been suggested that regional blood flow $(\mathrm{CBF})$ increases while oxygen consumption rate $\left(\mathrm{CMR}_{\mathrm{O} 2}\right)$ in the same area is not elevated commensurably [27], resulting in decreased extraction fraction and lower deoxyhemoglobin content per unit volume of brain tissue. Consequently, signal intensity in a BOLD sensitive image increases in regions of the brain engaged by a "task" relative to a resting, basal state. In this approach, the vast majority of images are acquired using $\mathrm{T}_{2}{ }^{*}$ weighting using gradient echoes. Few studies, especially recently with the introduction of high magnetic fields, have used Han-spin echoes.

High magnetic fields provide the capability for obtaining robust, BOLD-based functional maps with increased contrast, resolution, and specificity (i.e, accuracy). It has already been demonstrated (e.g, see [12,28-31]) that robust, reproducible high resolution $\mathrm{T}_{2} *$ BOLD maps can be obtained in the human brain at 7 Tesla, and in rodent brain up to 11.7 Tesla [32]. Examples of human brain functional 
imaging at 7 Tesla are illustrated in Fig. 3 for two slices obtained with $1 \times 1 \times 3 \mathrm{~mm}$ resolution in the visual cortex. Both negative and positive BOLD changes are clearly observed in these 7 Tesla functional maps (Fig. 3A). The figure also demonstrates the reproducibility of these images in consecutively acquired but separate maps. It can be seen that with the exception of a few pixels at the edges, the functional maps are highly reproducible, especially for the larger positive changes. In fact, the correlation coefficient that determines their significance of activation is also highly reproducible (Fig. 3C). In a separate study, we have reported that $\Delta 1 / \mathrm{T}_{2} *$ induced by neuronal activation was 2.1 fold larger at 7 Tesla compared to 4 Tesla, which led to images with larger areas of activation for the same threshold of statistical significance [30].

High resolution images, however, do not necessarily yield high accuracy maps. Basic image resolution dictated by contrast-to-noise ratio in fMRI (i.e, the magnitude of the signal changes induced by activation compared to imageto-image signal fluctuations), and accuracy in functional images are two independent parameters dictated by different processes. In discussing the spatial specificity of fMRI, we must also distinguish single condition vs. differential mapping. Differential mapping refers to functional images obtained by using two analogous but orthogonal activation states designed specifically to eliminate or suppress common signals; the functional image generated in this fashion correspond to a subtraction of the two conditions. In contrast, single condition mapping does not rely on a subtraction from a second orthogonal activated state. Mapping ocular dominance columns by stimulating one eye $v s$. the other in an alternating fashion is differential mapping. Stimulating one eye and using a dark state as the control would correspond to single condition mapping. Even if the imaging signals are not specific enough to be confined to the territory of one column, a functional map of the columns can be obtained in the differential image if a given group of columns respond slightly differently to the stimulation of each eye and, false (i.e, nonspecific) activation is induced equally by stimulating the two different eyes. Phase encoded mapping of multiple areas using an activation paradigm that cycles through all possible stimulations (as employed in the visual system (e.g, [33-35]) is also a kind of differential mapping because it suppresses common, nonmodulating components.

Single condition mapping at a high enough specificity to obtain columnar maps appears unlikely by $\mathrm{T}_{2} * \mathrm{BOLD}$ fMRI at any field strength. It was rigorously demonstrated that $\mathrm{T}_{2} * \mathrm{BOLD}$ fMRI method fails to generate single-condition functional images of iso-orientation domains in the cat cortex [36,37] at 4.7 Tesla. Although the image resolution was sufficiently good to detect columnar organizations associated with orientation preference in these studies, they were not observed. Furthermore, the images were not complementary when orthogonal orientations were used, and the highest "activity" was associated with a large draining vein,
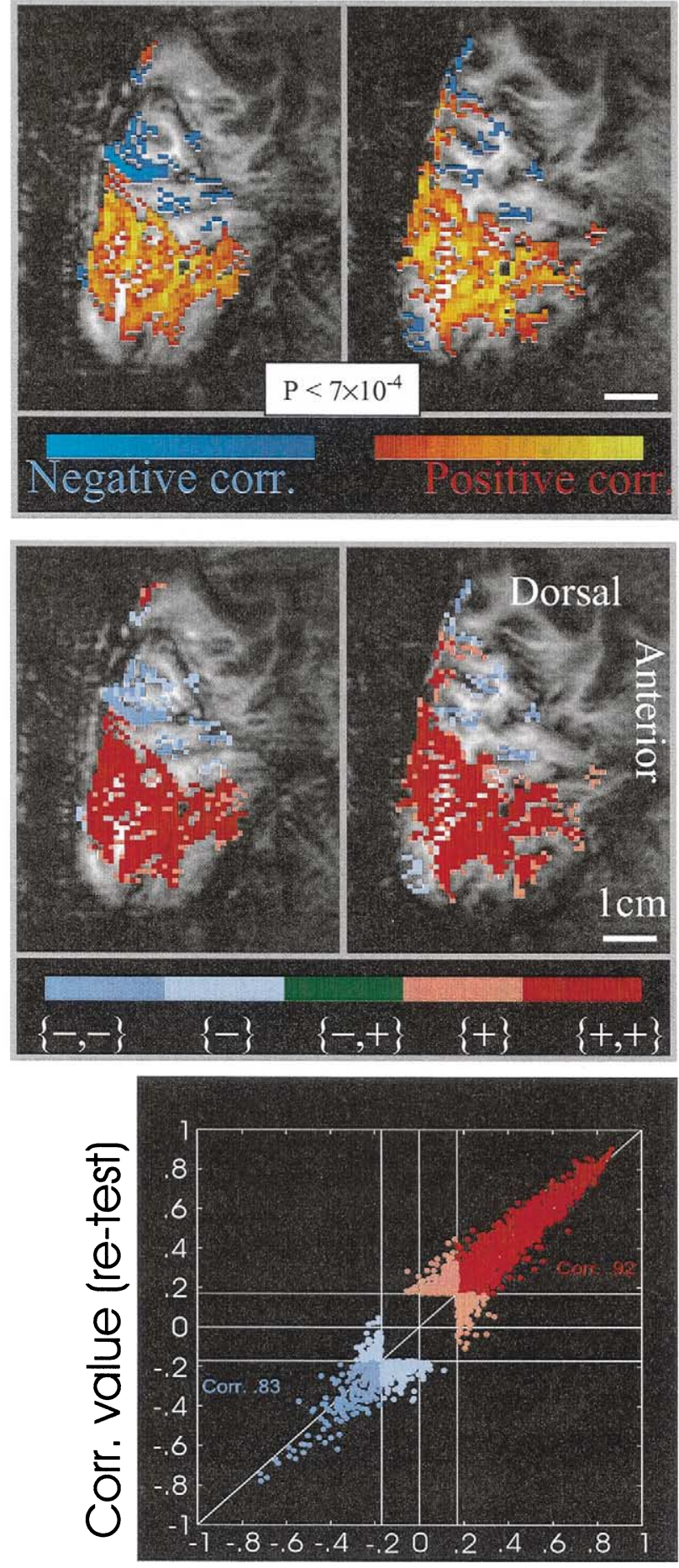

Corr. value (test)

Fig. 3. 7 Tesla, $1 \times 1 \times 3 \mathrm{~mm}^{3}$ fMRI functional images in two sagittal planes in the human visual cortex obtained with $\mathrm{T}_{2} *$ BOLD contrast, showing positive and negative signal intensity changes (A). Acquisition parameters were 4 segment gradient recalled echo EPI, TR $=150 \mathrm{~ms}$ per segment, $\mathrm{TE}=20 \mathrm{~ms}$ Reproducibility of the images are illustrated in (B) for two consecutive runs in the same subject; the pixels that are deemed to have shown a statistically significant increase are color coded as darker red for positive BOLD signals and darker blue for the negative BOLD signals. $\mathrm{C}$, Cross-correlation of all pixels with the activation template for the two runs against each other. Adapted from [28]. 


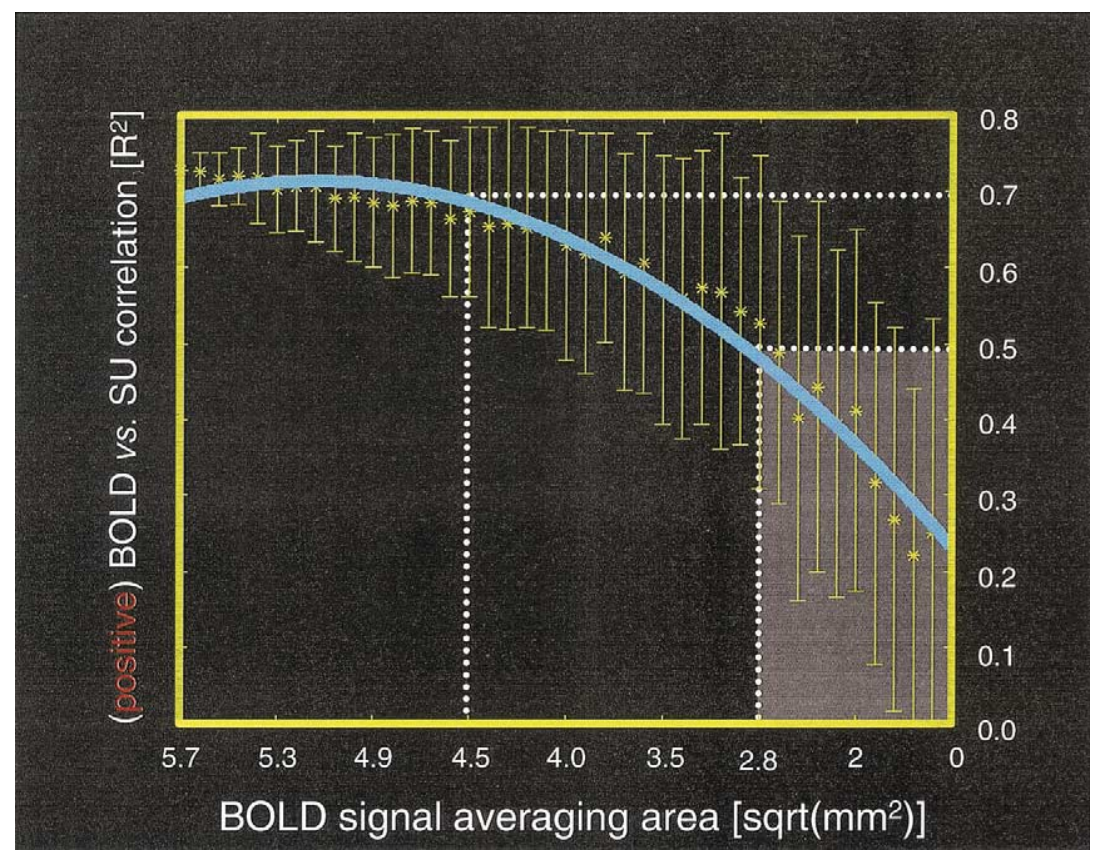

Fig. 4. The effect of voxel size on the relationship between BOLD fMRI signal amplitude and neuronal spiking. The spiking data were recorded from multiple sites over cat visual area 18 covering the activated area depicted in Fig. 1. When all spike data and BOLD data over a the large area of activation were averaged, a linear correlation was seen between BOLD amplitude at 4.7 Tesla and the spiking rate when the stimulation was modulated. BOLD single-unit data pairs from individual recording sites were reshuffled using methods of Monte Carlo permutation. Correlations between $n$ randomly shuffled single-unit sites and their corresponding $n$ BOLD sites (i.e, R2 between BOLD and single unit responses), were calculated. The mean and standard deviation for an exhaustively large population of random shufflings were calculated at each value of $n$ up to the maximum number of sites recorded, plotted against the nominal voxel size, calculated as $n \times 900 \mathrm{um}^{2}$ (cortical area within one voxel). The plot was then fitted with a conventional sigmoidal function, $\mathrm{y}=1 /(1.41$ $\left.+2.70 \exp \left(-0.151^{*} \mathrm{x}\right)\right)$. For each voxel size, the distribution of the neuronal qualities is also indicated by the standard deviation. The results depicted in this figure predict that the neuronal correspondence saturates around $\mathrm{R} 2=0.7$ at the voxel size of around $4.7 \times 4.7 \mathrm{~mm}^{2}$. Larger voxel sizes are suggested to be ineffective in further improving the level of neuronal correspondence. That is, the maximum amount of variance in the underlying neuronal modulation that can be explained with the variance of conventional $\mathrm{T}_{2}{ }^{*}$-based positive BOLD is about $70 \%$. Once the voxel size has been reduced to be smaller than $\sim 2.8 \times 2.8 \mathrm{~mm}^{2}$, only less only than $50 \%$ of the variance in the underlying neuronal modulation can be explained through the observed BOLD responses.

the sagittal sinus. Thus, spatial specificity in the submillimeter domain of iso-orientation columns does not exist in $\mathrm{T}_{2} *$ BOLD fMRI. Additional limitations on the accuracy of $\mathrm{T}_{2} *$ BOLD fMRI was provided by multiple site single unit recordings and fMRI studies on the same animal. These studies suggested that the limit of spatial specificity of $\mathrm{T}_{2}{ }^{*}$ BOLD may be in the 4 to $5 \mathrm{~mm}$ range for single-condition maps (Fig. 4) $[38,39]$. In this study, high-resolution $\mathrm{T}_{2}{ }^{*}$ BOLD fMRI was performed together with single-unit recording at multiple sites. The BOLD response was found to be proportional to the spiking rate when data from all recording sites was averaged and compared with the BOLD response from the entire area where it was deemed statistically significant. However, this correlation started breaking down when smaller and smaller areas were considered for the averaging of the two distinct measurements, in particular when the area started decreasing below approximately $4 \times$ $4 \mathrm{~mm}^{2}$. This result is also in excellent agreement with the numbers provided for the accuracy of fMRI maps at $1.5 \mathrm{~T}$ human brain using a phase-encoding method [35] where the full width at half maximum was estimated to be $3.5 \mathrm{~mm}$. Consistent with the observations, studies which have reported successful differential images of ocular dominance [41-44] have also reported that single condition mapping by $\mathrm{T}_{2} *$ BOLD fMRI was not feasible. Contrary, to all of these findings and the well documented presence of nonspecific contributions to $\mathrm{T}_{2} *$ BOLD fMRI, single condition imaging of human ocular dominance have been reported in one study [40].

The lack of spatial specificity in $\mathrm{T}_{2} *$ BOLD fMRI might reflect imprecise spatial-coupling between neuronal activity and the physiological and metabolic events that ultimately yield the functional images. Thus, blood flow increases that accompany enhanced neuronal activity might exceed the boundaries of active neurons. Alternatively, or in addition, the lack of spatial specificity could originate from the fact that vasculature plays a crucial role in the generation of MR detectable signals from deoxyhemoglobin changes that accompany neuronal activity. In fact, it is well documented that large "draining" vessels do contribute to the $\mathrm{T}_{2}{ }^{*}$ based BOLD signals [45].

The accuracy of spatial coupling between neuronal activity and increased blood flow can be evaluated using perfusion imaging (e.g, [46]). This of course requires that perfusion based functional maps do not contain contributions from large vessels. When blood flow to a volume of tissue increases, flow in the large arterial and venous blood vessel that supply or drain blood from that particular vol- 

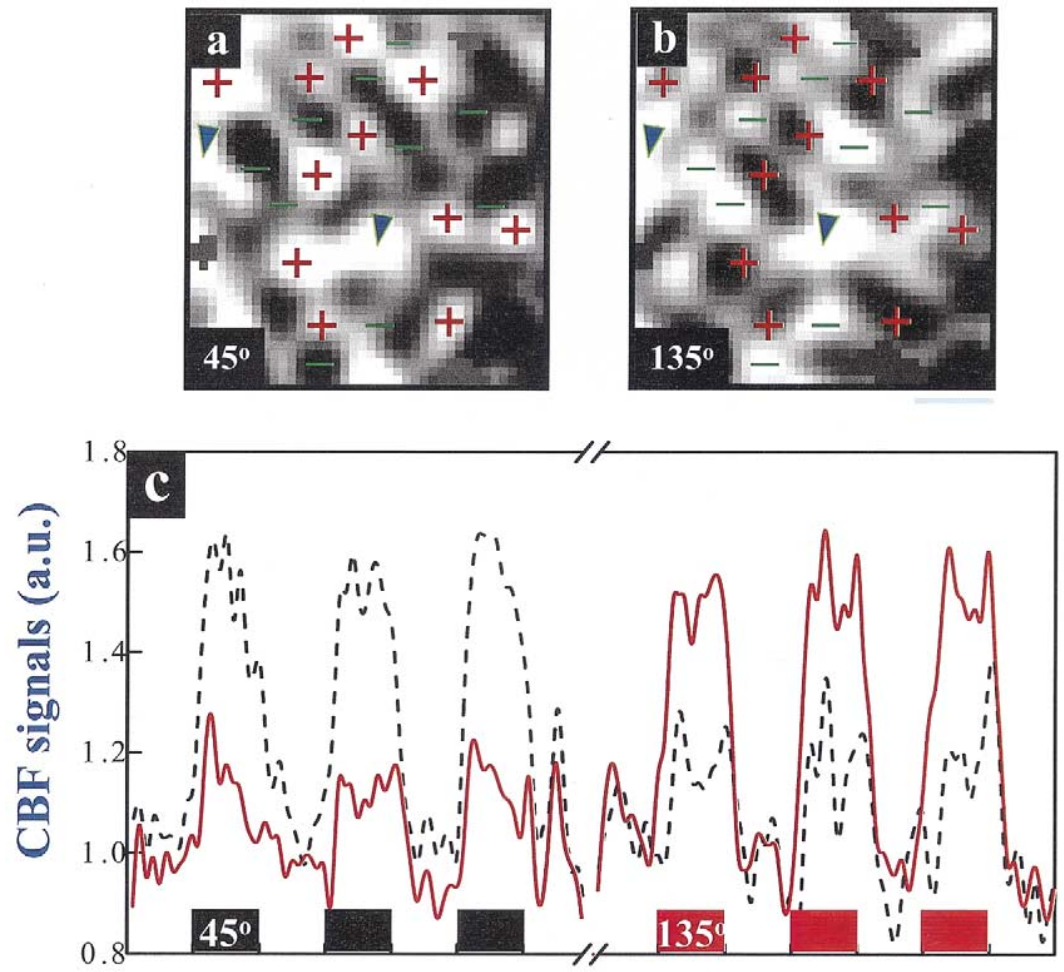

Fig. 5. Activation maps of two orthogonal iso-orientation domains in the cat visual cortex obtained separately with perfusion based mapping. A, T2* BOLD vs. Perfusion-based functional maps obtained with a single orientation. Note that while the single condition T2* BOLD map is contiguous for one orientation, contrary to what is expected, the corresponding perfusion map yields a patchy image consistent with an isorientation domain. B, Perfusion-based images obtained with two orthogonal orientations $\left(45^{\circ}\right.$ and $135^{\circ}$ gratings), demonstrating their complementarity. Each map was acquired as a single condition map where the grating of one orientation was either moving back and forth (activation condition) or static (control condition). Bottom trace shows the blood flow (perfusion) response to in all the voxels identified as "activated" either by the $45^{\circ}$ or $135^{\circ}$ gratings for the two orthogonal stimulations. All voxels identified as "activated" for $45^{\circ}$ orientation display a large perfusion increase during stimulation by this orientation gratings and show a smaller but detectable perfusion increase in response to the $135^{\circ}$ gratings. The opposite of this is observed for the voxels identified as activated for $135^{\circ}$ gratings. A marked perfusion increase $(\sim 55 \%)$ following $45^{\circ}$ or $135^{\circ}$ stimulus was observed in the regions tuned to these orientations, while the stimulation with the orthogonal orientation lead to a $3.3 \pm 0.6$ fold smaller perfusion increase in the same region. Adapted from reference [58]

ume of tissue must also increases due to conservation of mass; thus, blood vessel dilation produced by neuronal activation propagates to distant blood vessels [52]. However, long tagging times ( $\sim 2 \mathrm{~s})$ [53] eliminate arterial component from perfusion images. The long tagging times, on the other hand, may lead to the tagged spins appearing in the venous side, thus leading to false activation in the veins. At high magnetic fields, the spin-spin relaxation rate $\left(\mathrm{T}_{2}\right)$ of venous blood is very short $[30,55]$ so that this effect can be selectively eliminated by a brief delay after excitations of spins but before image acquisition. Accordingly, perfusionbased fMRI maps have been shown to co-localize with $\mathrm{Mn}^{+2}$ uptake [56], a marker of calcium dependent synaptic activity [57].

In the absence of large vessel contributions, perfusionbased fMRI can be used to examine the critical physiological question related to specificity of blood flow increases. Namely, are perfusion changes confined accurately to the region of increased neuronal activity in the spatial scale of columnar organizations? Such a study was performed recently using the iso-orientation columns in the cat visual system [58]. It demonstrated that while perfusion increases that follow neuronal activation were not "perfectly" localized at the iso-orientation column level, the difference between active and neighboring inactive columns was large and permitted single condition mapping (Fig. 5). This contradicts the concept based on optical imaging data that blood flow responses are not specific in the columnar scale and extend several millimeters beyond the area of activation. However, the MR results are not necessarily contradictory to the optical imaging data themselves. Optical imaging does not measure blood flow (rather, the amount of hemoglobin, which is determined by blood volume and red cell density), and cannot selectively eliminate noncapillary contributions. In addition, the "contrast" in these two measurements (i.e, the difference detected between the active and inactive column) are likely to be smaller for CBV, since fractional CBV changes are expected to be smaller than fractional blood flow changes [59]. Recent studies in fact demonstrate that optical imaging based on CBV changes can resolve columnar structures provided large vessel effects are eliminated, in total agreement with the perfusion imaging results [60].

Thus, the explanation for the failure of $\mathrm{T}_{2} * \mathrm{BOLD}$ fMRI 
to depict columnar organization in single-condition mapping, for having a spatial accuracy in the 3 to $5 \mathrm{~mm}$ range (when assessed either by electrophysiology or retinotopy in the human brain) is the presence of large vessel contributions to $\mathrm{T}_{2}{ }^{*}$ BOLD fMRI. The deoxyhemoglobin changes which are initiated at the point of increased neuronal activity do not remain stationary and propagate into large "draining" vessels. Thus, they appear, incorrectly, as "activation" distant from the actual site of neuronal activity. The extent of this contribution is expected to depend on the magnetic field magnitude because it arises both from blood and from extravascular BOLD effect (e.g, see [61-64]. The extravascular BOLD effect will increase linearly with magnetic field magnitude while intravascular effect diminishes rapidly with magnetic field magnitude beyond about 3 Tesla [55].

The presence of large vessel contribution in $\mathrm{T}_{2} * \mathrm{BOLD}$ fMRI images even at 7 Tesla can be seen if perfusion based images can be compared with $\mathrm{T}_{2}{ }^{*}$ BOLD fMRI. Both because of the enhanced SNR and the long $\mathrm{T}_{1}$, high fields provide advantages for perfusion based functional imaging. In high resolution perfusion images that were obtained at 7 Tesla for the first time [13], the activity was found to be confined to the gray matter ribbon; in contrast, the $\mathrm{T}_{2}$ * BOLD fMRI images showed highest intensity changes not in the cortex but in the cerebral spinal fluid space (CSF) in the sulcus (Fig. 6). Within the cortical gray matter, there are 50- to 100-micron veins separated by 1 to $1.5 \mathrm{~mm}$ that drain the capillaries. These are the blood vessels that can be seen in high resolution $\mathrm{T}_{2}{ }^{*}$-weighted images as dark lines traversing the gray matter perpendicular to the cortical surface. These small veins drain immediately into similarly sized or somewhat larger veins on the cortical surface. Since these vessels drain a small territory, the deoxyhemoglobin alterations induced at the active site at the terminal ends of the capillaries are mostly, if not fully, preserved in going from capillaries to these small diameter post-capillary vessels. Consequently, these small intracortical and surface venules and veins must have a significant extravascular effect, one that must exceed the capillary contribution to extravascular BOLD since, unlike the capillaries, they are large enough to be outside the dynamic averaging regime that diminishes the BOLD effect (and, hence, converts it from a $\mathrm{T}_{2} *$ to an apparent $\mathrm{T}_{2}$ phenomenon). The small veins located on the cortical surface, are likely the source of intense but false activation seen within sulci in human $\mathrm{T}_{2}{ }^{*}$ BOLD images at 7 Tesla [13] (and Fig. 6).

These images, faithful to the borders of the perfusion increase without any large vessel contribution, can be obtained also with Hahn Spin Echo (HSE) BOLD at high but not low magnetic fields. HSE fMRI responds to apparent $\mathrm{T}_{2}$ (as opposed to $\mathrm{T}_{2}{ }^{*}$ ) changes originating from diffusion of water in the presence of magnetic field gradients generated in the extravascular space around microvasculature, as well as from exchange of water in and out of red blood cells in blood itself $[61,63,65]$. The former provides spatial specificity in the 100-micron spatial scale because capillaries are separated on the average by $25 \mu \mathrm{m}$ [66]. The blood effect, however, can be associated with both large and small blood vessels and hence degrades spatial specificity of fMRI. However, the apparent $T_{2}$ of venous blood decreases quadratically with magnetic field magnitude [67] and is diminished from $\sim 180 \mathrm{msec}$ at 1.5 Tesla [68] to $\sim 6 \mathrm{msec}$ at 9.4 Tesla [54], significantly smaller than brain tissue $T_{2}$ and the TE values that would be used at such field strengths. HSE BOLD signals associated with capillaries are inherently small and undetectable at low magnetic fields. But they are expected to increase supralinearly with magnetic field. They approach potentially useful dimensions at 3 Tesla [69] (provided blood contribution that still exists at this field strength is suppressed) and are large enough to yield microvasculature-based high resolution maps even in the human brain at 7 Tesla (Fig. 7) and 9.4 Tesla [54]. As in perfusion imaging, HSE BOLD techniques are expected to yield columnar level mapping. That they are capable of distinguishing among different layers has already been shown, as indicated in Fig. 7. In these HSE fMRI images, the activation follows the cortical gray matter with the largest intensity in the middle layers rather than in the outer surface and in the intrasulcal space. The appearance of the largest intensity in the middle layers (rather than the cortical surface) is expected since the inputs from the lateral geniculate nuclei terminate in layer 4 . This is also the layer with the highest capillary density and cytochorome oxidase activity.

In principle, it is possible to obtain functional images with better spatial specificity than perfusion if one can map the changes in cerebral oxygen consumption rate $\left(\mathrm{CMRO}_{2}\right)$. $\mathrm{CMRO}_{2}$ increases must occur through increased activity of the mitochondria in the "activated" neurons. The mitochondrial density is high in the synapse rich regions, predominantly in the dendrites [70]. It might be possible to image $\mathrm{CMRO}_{2}$ increases directly using the magnetic isotope of oxygen $\left({ }^{17} \mathrm{O}\right)$ (e.g, [71-73] and references therein). $\mathrm{CMRO}_{2}$ increases can also be mapped indirectly through its perturbations of deoxyhemoglobin content. It has been shown that optical imaging of intrinsic signals in the cat and monkey visual cortex display a transient and small signal change ascribed to the deoxyhemoglobin increase before the onset of a larger increase in blood flow [74-78]. In this explanation, it is the lag in the blood flow response which provides the temporal opportunity to detect the deoxyhemoglobin increase. The optical imaging data also showed that this deoxyhemoglobin increase yielded better maps of iso-orientation or ocular dominance columns than the signals associated with the hyperoxygenated state. Deoxyhemoglobin increase, however, can only be co-localized with elevated $\mathrm{CMRO}_{2}$ at early time points after the onset of $\mathrm{CMRO}_{2}$ elevation. Even if subsequent blood flow enhancement did not occur, and the deoxyhemoglobin increase was the only response detected, this deoxyhemoglobin increase would co-localize with enhanced neuronal activity initially, but later would propagate down the vasculature and appear in the venous system as discussed previously. 

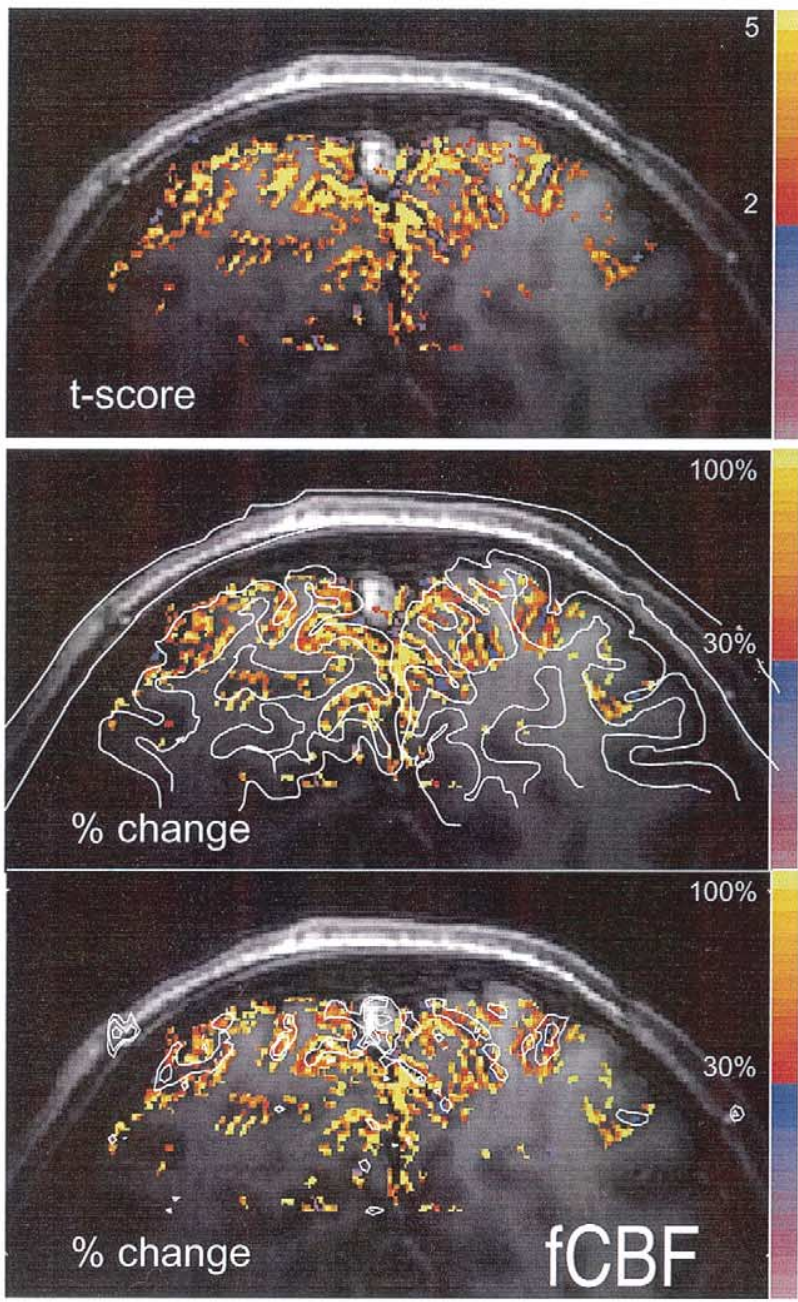
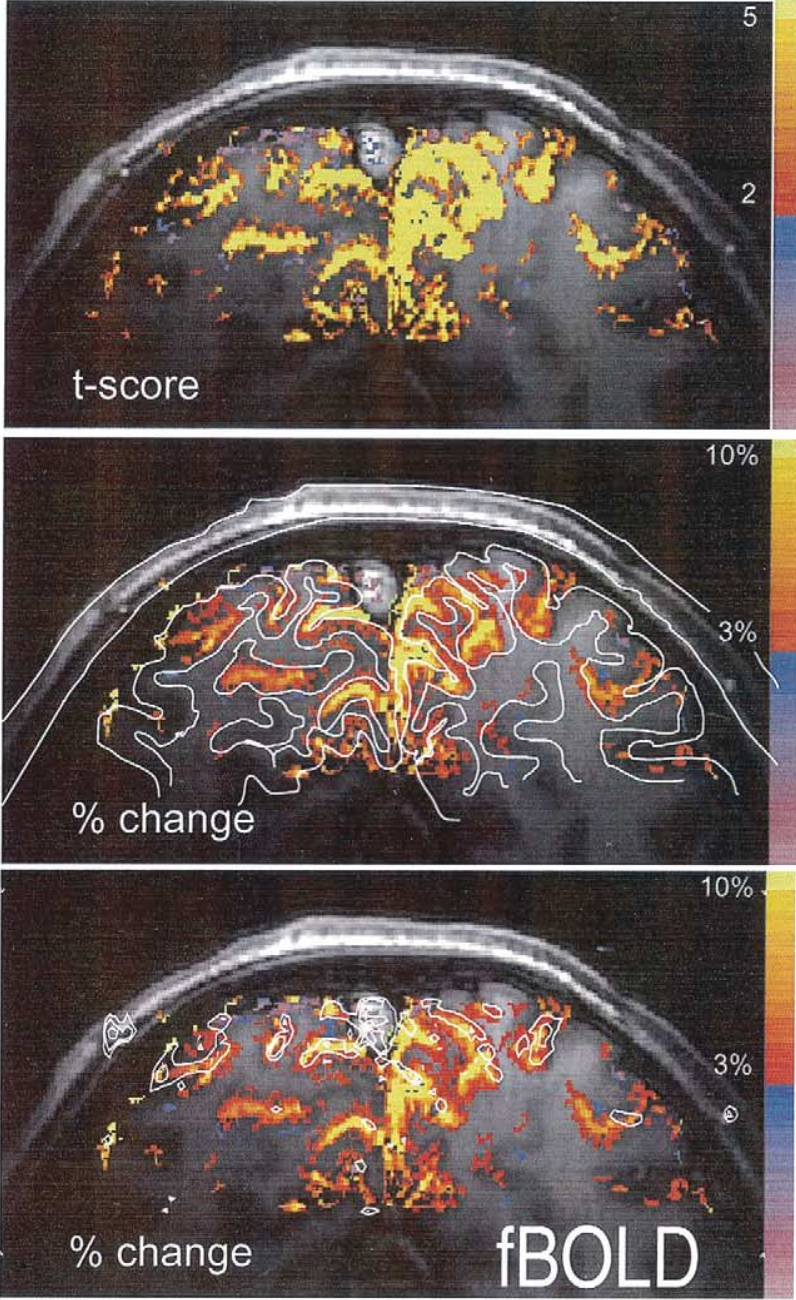

Fig. 6. 7 Tesla functional perfusion (left column) and $\mathrm{T}_{2} *$ BOLD (right column) maps obtained in the human brain with $0.9 \times 0.9 \times 3 \mathrm{~mm}^{3}$ spatial resolution during visual stimulation. The $\mathrm{T}_{2} *$ BOLD acquisition was interleaved with the acquisition of the fCBF maps. Results represent a $t$-test analysis with $p<0.05$. Percent changes range from $30 \%$ to over $100 \%$ for fCBF and from $3 \%$ to over $10 \%$ for fBOLD, respectively. Anatomic contours of the gray matter are overlaid onto the \%change map in the middle row.

The transient deoxyhemoglobin increase would yield a negative signal change in a BOLD-weighted MR image. Such a "dip" has been observed in human fMRI experiments [31,79-84] and in animal models [36,37,85]. However, both in optical imaging and fMRI literature, the observation of this "dip" has been controversial. The source of this controversy in the early human fMRI studies has been the failure of several laboratories to detect this effect at 1.5 Tesla studies. However, this is a small effect at low magnetic fields but was shown to increase substantially with magnetic field magnitude [31] to yield easily detectable signals at 7 Tesla. Recently, in intra-operative studies in the human brain, the functional maps obtained from this early "dip" was also detected and shown to co-localize with electrical recordings, whereas $\mathrm{T}_{2} *$ BOLD maps did not [84]. In anesthetized animal models, this small dip has not been highly reproducible presumably because of the perturbations of anesthesia on the animal physiology. When observed, it was found to yield accurate maps at the iso- orientation columnar level [36,37]. However, this early negative response corresponding to deoxyhemoglobin increase is a very small effect. Furthermore, in order to obtain accurate maps from it, one must restrict the observation window to early time points where the signals are even smaller. Thus, as a general high resolution MR imaging approach, it suffers from low contrast-to-noise.

\section{Imaging using low gyromagnetic nuclei}

Low gyromagnetic nuclei can in principle be used to obtain unique biologic information. Atoms with magnetic nuclei such as phosphorus, oxygen, carbon (with magnetic isotopes ${ }^{31} \mathrm{P},{ }^{17} \mathrm{O},{ }^{13} \mathrm{C}$ ) all appear in abundance within cells. Ions such as sodium and potassium (with magnetic isotopes ${ }^{23} \mathrm{Na},{ }^{33} \mathrm{~K}$ ) are critical in cellular function. However, these low gyromagnetic nuclei suffer from limitation in sensitivity. Not only is the inherent MR sensitivity for detection of 


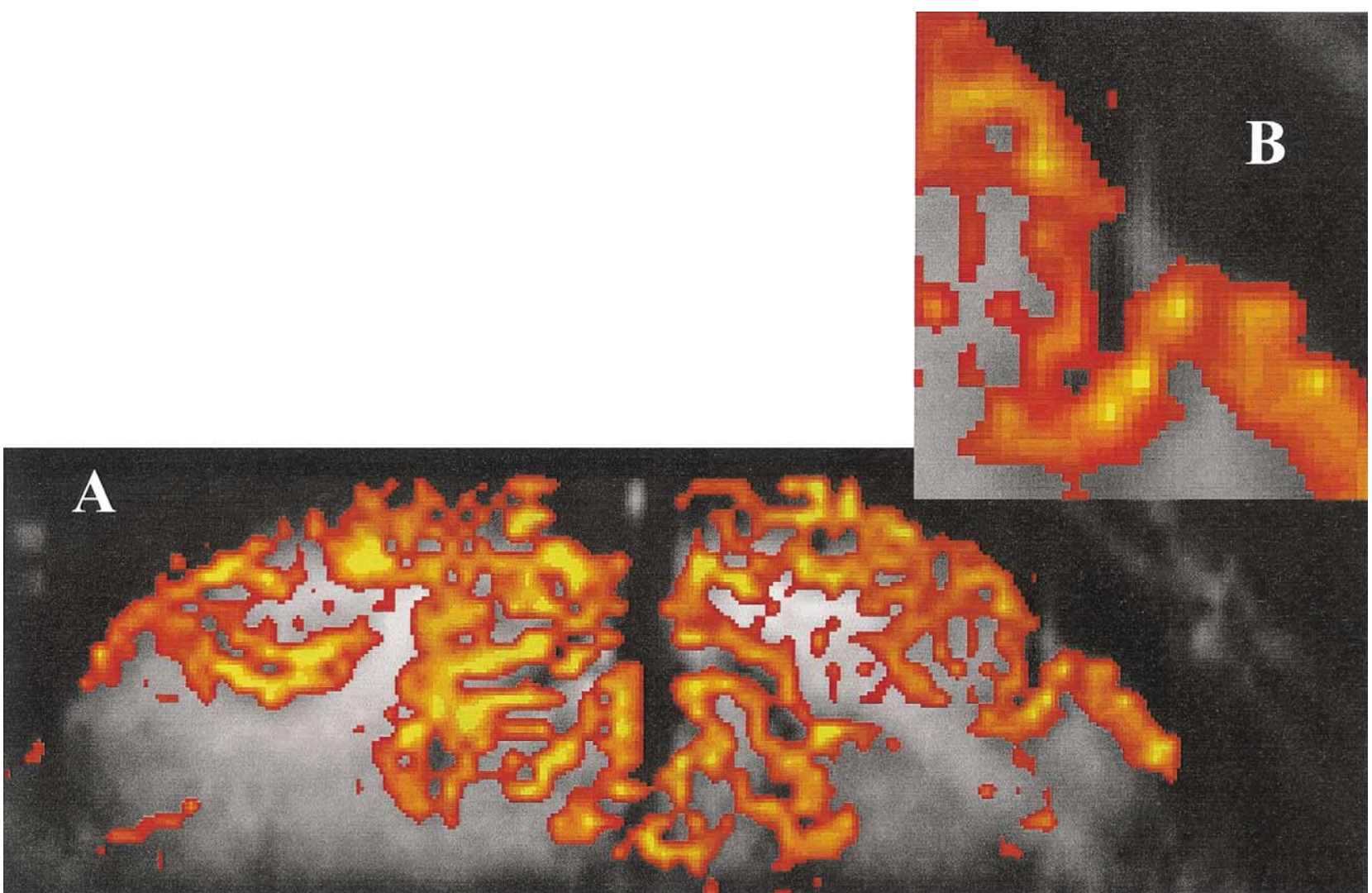

Fig. 7. Spin-echo images $\left(0.5 \times 0.5 \times 2 \mathrm{~mm}^{3}\right)$ of the visual activation in the human visual cortex obtained at 7 Tesla. The data demonstrate that high spatial resolution images van be obtained robustly in the human brain at 7 Tesla using the normally weak but more accurate Hahn-Spin Echo Imaging signals. The insert (B) shows an expanded view around a sulcus demonstrating that the highest intensity HSE BOLD activation is in the middle layers (unlike $\mathrm{T}_{2} * \mathrm{BOLD}$ ) and the CSF space in the sulcus is free of high intensity changes coupled to "false" activation, unlike $\mathrm{T}_{2} *$ BOLD (as shown in Fig. 6, right column). Note also the absence of BOLD signal intensity changes between the two hemispheres, again, unlike the $\mathrm{T}_{2} *$ BOLD images shown in Fig. 6, right column. Single Shot Spin Echo Planar Imaging with field of view reduction to $3.2 \mathrm{~cm} \times 12.8 \mathrm{~cm}(64 \times 256)$ (partial Fourier) TE/TR: $70 \mathrm{msec} / 2 \mathrm{~s}$. From [123].

these nuclei low because of their small magnetic moments, their abundance in the cells as a single chemical species (i.e, with one chemical shift) is also low. Therefore, sensitivity gains that can be realized with increasing magnetic fields become critically important for these nuclei.

At high frequencies attained by protons at magnetic fields like 7 or 9.4 Tesla, signal-to-noise ratio dependence on magnetic field becomes complex and approximately linearly dependent on magnetic field magnitude. However, for low frequencies or for nonconductive samples, the magnetic field dependence of SNR can be approximately quadratic and is expressed by the relationship

$$
\mathrm{SNR} \infty \mathrm{B}_{0}^{\beta}\left(\mathrm{T}_{2}^{*} / \mathrm{T}_{1}\right)^{1 / 2}
$$

where, based on theoretical considerations, the constant $\beta$ was suggested to be $7 / 4$ [86,87]. Motivated by the SNR gains expected from the availability of high field magnets, in recent years, we have examined the possibility of using ${ }^{17} \mathrm{O}$ for monitoring oxidative metabolism in intact animals and ultimately humans at 7 and 9.4 Tesla at resonance frequencies of 40 and $54 \mathrm{MHz}$, respectively.

\subsection{Oxygen 17 imaging}

${ }^{17} \mathrm{O}$ spin is the only stable oxygen isotope having a magnetic moment that can be detected by the NMR approach. It has a spin quantum number $(I=5 / 2)$ greater than one half and possesses an electric quadrupole moment. This is the dominant source of $T_{1}$ and $T_{2}$ relaxation [88] for this nucleus. In the case of water molecule, for which the extreme narrowing limit (i.e, $\tau_{\mathrm{c}} \omega \ll 1$, where $\tau_{\mathrm{c}}$ is the rotational correlation time and $\omega$ is Lamar frequency in radians/ sec) is applicable (except for the bound water) the values of $\mathrm{T}_{1}$ and $\mathrm{T}_{2}$ can be estimated by using the equation

$$
\frac{1}{T_{2}} \cong \frac{1}{T_{1}} \cong \frac{3}{40}\left(\frac{2 I+3}{I^{2}(2 I-1)}\right)\left(1+\frac{\eta^{2}}{3}\right)\left(\frac{\pi e^{2} Q q}{h}\right)^{2} \tau_{c}
$$

where the term of $\left(\pi e^{2} Q q / h\right)$ is the quadrupoler coupling constant and is equal to $6.7 \mathrm{MHz}$ (or $4.21 \cdot 10^{7}$ radian/s) for the ${ }^{17} \mathrm{O}$ nucleus, $\eta$ is an asymmetry parameter $(0 \leq \eta \leq 1)$ [88].

Because both $\eta$ and $\tau_{c}$ are independent of the magnetic field strength, $\mathrm{T}_{1}$ and $\mathrm{T}_{2}\left(\right.$ or $\left.\mathrm{T}_{2}{ }^{*}\right)$ for the ${ }^{17} \mathrm{O}$ spins should be 
field independent. If the $\tau_{c}$ value of $8.5 \times 10^{-12} \mathrm{~s}$ is used for bulk water at $298 \mathrm{~K}$ [89], then estimated $\mathrm{T}_{2}$ and $\mathrm{T}_{1}$ should be between $2.8 \mathrm{~ms}$ (for $\eta=0$ ) and $2.1 \mathrm{~ms}$ (for $\eta=1$ ). The actual ${ }^{17} \mathrm{O} \mathrm{T}_{2}$ value should be smaller than the ${ }^{17} \mathrm{O} \mathrm{T}_{1}$ value due to the significant contributions of the ${ }^{17} \mathrm{O}-{ }^{1} \mathrm{H}$ scalar coupling and the proton chemical exchange to the ${ }^{17} \mathrm{O} \mathrm{T}_{2}$ relaxation processes [90]. Consistent with these expectations, in experiments conducted at 4.7 and 9.4 Tesla, the ${ }^{17} \mathrm{O}$ relaxation times in water were found to be short, similar, and field independent for the rat brain $\left(\mathrm{T}_{2}=3.03 \pm 0.08\right.$ $\mathrm{ms}, \mathrm{T}_{1}=4.47 \pm 0.14 \mathrm{~ms}$ at 4.7 Tesla; $\mathrm{T}_{2}=3.03 \pm 0.09$ $\mathrm{ms}, \mathrm{T}_{1}=4.84 \pm 0.18 \mathrm{~ms}$ at 9.4 Tesla), as well as for the saline solution at the room temperature $\left(\mathrm{T}_{2}=4.28 \pm 0.08\right.$ $\mathrm{ms}, \mathrm{T}_{1}=6.59 \pm 0.10 \mathrm{~ms}$ at $4.7 \mathrm{Tesla} ;$ and $\mathrm{T}_{2}=4.09 \pm$ $0.06 \mathrm{~ms}, \mathrm{~T}_{1}=6.52 \pm 0.12 \mathrm{~ms}$ at 9.4 Tesla) [91].

The ${ }^{17} \mathrm{O}$ NMR sensitivity was evaluated at 9.4 Tesla and 4.7 Tesla in the rat brain and in saline solution [91]. A consistent SNR gain of approximately fourfold was observed at 9.4 Tesla as compared to 4.7 Tesla, indicating an approximately theoretically maximum power dependence of SNR on $\mathrm{B}_{0}$. These experimental results demonstrate the significant advantage provided by high field strength for direct detection of ${ }^{17} \mathrm{O}$ NMR signal. This trend for increasing ${ }^{17} \mathrm{O}$ NMR sensitivity is expected to hold beyond 9.4 Tesla.

With the dramatic sensitivity gains realized at 9.4 Tesla, it is possible to obtain $3-\mathrm{D}{ }^{17} \mathrm{O}$ imaging and utilize it for calculation of oxygen consumption rates. The dynamic change in cerebral $\mathrm{H}_{2}{ }^{17} \mathrm{O}$ concentration during an inhalation of ${ }^{17} \mathrm{O}_{2}$ is determined by three parallel processes: 1) oxygen consumption generating the metabolic $\mathrm{H}_{2}{ }^{17} \mathrm{O}$ from ${ }^{17} \mathrm{O}$ in the brain; 2) $\mathrm{H}_{2}{ }^{17} \mathrm{O}$ washout from the brain; and 3) flow recirculation bringing extra $\mathrm{H}_{2}{ }^{17} \mathrm{O}$ into the brain. The mass balance equation of labeled $\mathrm{H}_{2}{ }^{17} \mathrm{O}$ concentrations during an inhalation of ${ }^{17} \mathrm{O}_{2}$ is given by

$$
\begin{aligned}
\frac{d C_{b}(t)}{d t}= & 2 \alpha f_{1} \mathrm{CMRO}_{2}+m C B F\left(f_{2} C_{a}(t)\right. \\
& \left.-\frac{n C_{b}(t)}{\lambda}\right) .
\end{aligned}
$$

where $\mathrm{C}_{\mathrm{a}}(\mathrm{t}), \mathrm{C}_{\mathrm{b}}(\mathrm{t})$ are the time-dependent $\mathrm{H}_{2}{ }^{17} \mathrm{O}$ concentrations in excess of the natural abundance $\mathrm{H}_{2}{ }^{17} \mathrm{O}$ concentration level in the arterial blood, and the brain tissue, respectively; $\alpha$ is the ${ }^{17} \mathrm{O}$ enrichment fraction of inhaled ${ }^{17} \mathrm{O}_{2}$ gas. The parameters $\mathrm{C}_{\mathrm{b}}, \mathrm{C}_{\mathrm{a}}$ can be measured by ${ }^{17} \mathrm{O}$ NMR and they can be calibrated using the natural abundance $\mathrm{H}_{2}{ }^{17} \mathrm{O}$ concentration (20.35 $\mu$ mole per gram brain water for brain tissue, and $\mu$ mol per gram blood water for blood, calculated from natural abundance $\mathrm{H}_{2}{ }^{17} \mathrm{O}$ enrichment of $0.037 \%$ and the molecular weight of $\mathrm{H}_{2}{ }^{17} \mathrm{O}=19.0$ ). The mass balance equation for $\mathrm{C}_{\mathrm{b}}$ is written in terms of preferred units $\mu \mathrm{mol} /(\mathrm{g}$ brain water $)$ for $\mathrm{C}_{\mathrm{b}}(\mathrm{t})$, $\mu \mathrm{mol} /(\mathrm{g}$ blood water $)$ for $\mathrm{C}_{\mathrm{a}}(\mathrm{t})$. The unit used most commonly for $\mathrm{CMRO}_{2}$ is $\mu$ mole/ $\mathrm{min} /(\mathrm{g}$ brain tissue $)$ and is retained. This dictates the use of two unit conversion factors, $f_{1}=1.266$ and $f_{2}=1.05$, to achieve consistency of units among all parameters used $[92,93]$. The equation above assumes water in the brain tissue is in equilibrium with water in the venous blood (i.e, fast water exchange across capillaries); thus, $f_{2} \mathrm{C}_{\mathrm{v}}(\mathrm{t})=$ $\mathrm{C}_{\mathrm{b}}(\mathrm{t}) / \lambda$ where $\mathrm{C}_{\mathrm{v}}$ is the $\mathrm{H}_{2}{ }^{17} \mathrm{O}$ concentrations in excess of the natural abundance $\mathrm{H}_{2}{ }^{17} \mathrm{O}$ concentration level in venous blood and $\lambda$ is the brain/blood partition coefficient $(\approx 0.90)$ in units of $(\mathrm{ml} \mathrm{blood}) /(\mathrm{g}$ brain tissue $)$ [94]. The parameter $m$ is a correction factor accounting for the limited permeability of water because water is not totally freely diffusible across the brain-blood barrier; in the CBF range attained in these studies, $m$ is 0.84 [95]. The constant $n$ is another correction factor that accounts for the restriction on the permeability of the $\mathrm{H}_{2}{ }^{17} \mathrm{O}$ generated through oxidative metabolism in the mitochondria ("metabolic" $\mathrm{H}_{2}{ }^{17} \mathrm{O}$ ) during an inhalation of ${ }^{17} \mathrm{O}_{2}$. This additional restriction is included in our modeling because we have observed that the washout rate of the metabolic $\mathrm{H}_{2}{ }^{17} \mathrm{O}$ after the cessation of ${ }^{17} \mathrm{O}_{2}$ inhalation was significantly slower than the washout rate of the $\mathrm{H}_{2}{ }^{17} \mathrm{O}$ that permeates brain tissue subsequent to a bolus injection of $\mathrm{H}_{2}{ }^{17} \mathrm{O}$ through the internal carotid artery in the rat [96].

The $\mathrm{CMRO}_{2}$ value can, therefore, be precisely calculated from ${ }^{17} \mathrm{O}$ imaging studies using the complete model if all parameters of $\mathrm{C}_{\mathrm{b}}(\mathrm{t}), \mathrm{CBF}, n$ and $\mathrm{C}_{\mathrm{a}}(\mathrm{t})$ can be determined experimentally for the same brain. However, experiments have shown that at least in the rat model, $\mathrm{C}_{\mathrm{a}}(\mathrm{t})$ can be approximated as a linear function of the inhalation time (i.e, $\mathrm{C}_{\mathrm{a}}(\mathrm{t}) \approx A t$, where $A$ is a constant and $t$ represents time) or even ignored for short inhalation times [91].

A fundamental limitation of spatial resolution using the ${ }^{17} \mathrm{O}$ imaging approach will be water diffusion in the brain since water is usually assumed freely diffusible. The apparent diffusion constant of water in the rat brain has been measured to be $\sim 10^{-3} \mathrm{~mm}^{2} / \mathrm{s}$ [97] with small directiondependent variations due to anisotropy. The average "lifetime" of a $\mathrm{H}_{2}{ }^{17} \mathrm{O}$ molecule in the brain tissue after it is formed and before it is washed out by blood flow is given by $\lambda / \mathrm{CBF}$ which is $\sim 1 \mathrm{~min}$ since $\mathrm{CBF} \sim 1 \mathrm{ml} / \mathrm{g} / \mathrm{min}$. Thus, the diffusion distance during this lifetime is $\sim 0.25 \mathrm{~mm}$. Therefore, major limitation on spatial resolution for imaging $\mathrm{CMRO}_{2}$ will be determined by the ${ }^{17} \mathrm{O}$ NMR sensitivity and not the diffusion of water.

We have recently investigated the feasibility for developing the ${ }^{17} \mathrm{O}$ NMR approach for imaging $\mathrm{CMRO}_{2}$ in a small animal model during a brief inhalation of ${ }^{17} \mathrm{O}_{2}$ gas at 9.4 Tesla [93]. Fig. 8A demonstrates stacked plots of ${ }^{17} \mathrm{O}$ spectra of cerebral $\mathrm{H}_{2}{ }^{17} \mathrm{O}$ from one representative voxel (0.1 $\mathrm{ml}$ volume) before (natural abundance), during and after a 2-min inhalation of ${ }^{17} \mathrm{O}_{2}\left(72 \%{ }^{17} \mathrm{O}\right.$ enrichment $)$ gas [93]. The ${ }^{17} \mathrm{O}$ signal intensity of cerebral $\mathrm{H}_{2}{ }^{17} \mathrm{O}$ is characterized by three distinct phases: 1) constant before the ${ }^{17} \mathrm{O}_{2}$ inhalation; 2) approximately linear increase during the ${ }^{17} \mathrm{O}_{2}$ inhalation; and 3) approximately exponential decrease after the cessation of ${ }^{17} \mathrm{O}_{2}$ inhalation and approaching a new steady concentration within a short recovery time $(<10$ 


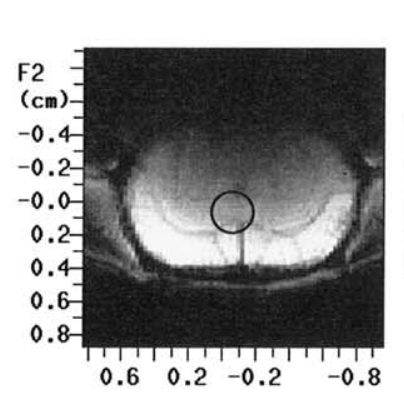

A
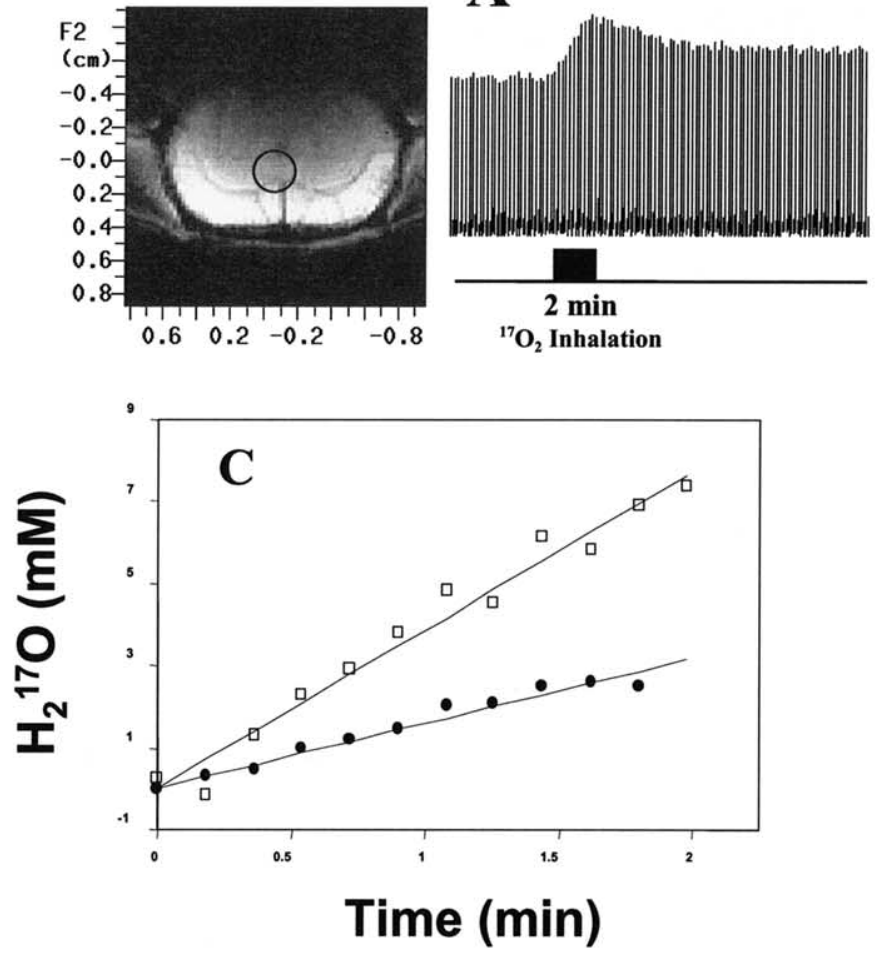
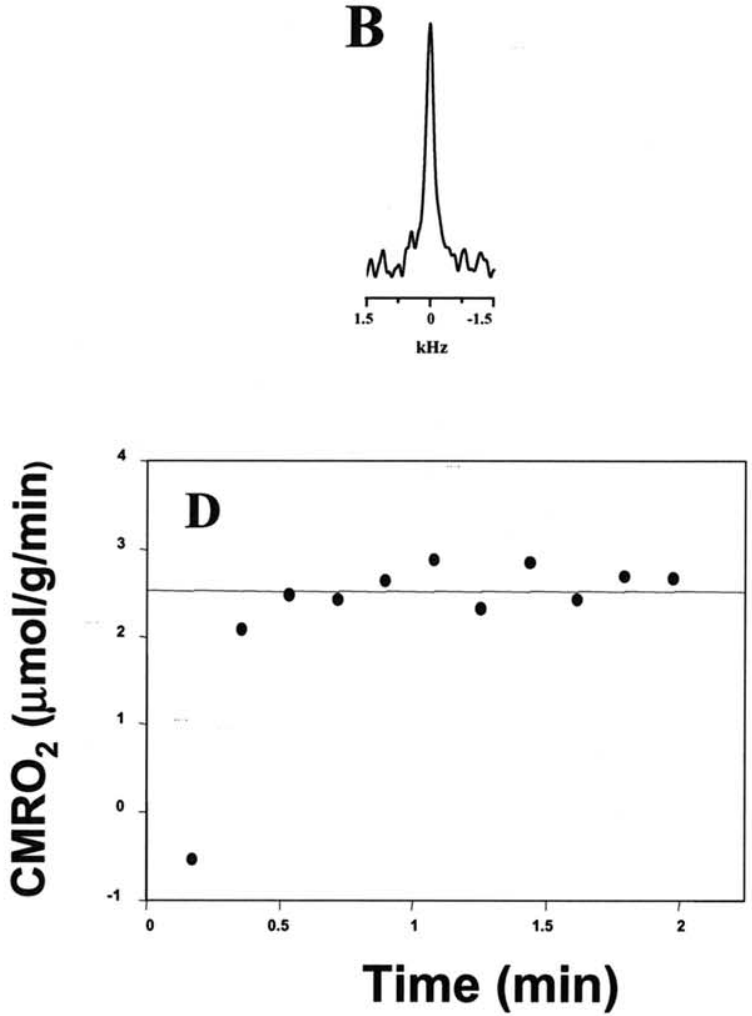

Fig. 8. A, Stacked plots of the cerebral $\mathrm{H}_{2}{ }^{17} \mathrm{O}$ spectra from one representative voxel $(0.1 \mathrm{ml}$ voxel size) as indicated by the circle in the anatomic image (left insert) acquired before (natural abundance), during (as indicated by the dark bar under the stacked plots) and after a 2 -min ${ }^{17} \mathrm{O}_{2}$ inhalation. ${ }^{17} \mathrm{O}$ spectrum of natural abundance $\mathrm{H}_{2}{ }^{17} \mathrm{O}$ in the rat carotid artery blood $(\sim 7 \mu \mathrm{L})$ obtained using the implanted RF coil before inhalation of ${ }^{17} \mathrm{O}_{2}(\mathrm{~B})$ and time course $(\mathrm{C})$ of ${ }^{17} \mathrm{O}$ MR signals of $\mathrm{C}_{\mathrm{a}}(\mathrm{t})$ in one carotid artery (circle symbol) and $\mathrm{C}_{\mathrm{b}}(\mathrm{t})$ from a representative voxel in the rat brain (square symbol) during inhalation of ${ }^{17} \mathrm{O}_{2}$. D, Plot of the calculated $\mathrm{CMRO}_{2}$ values using the complete modeling as a function of inhalation time.

min). The ${ }^{17} \mathrm{O}$ NMR sensitivity achieved at 9.4 Tesla makes it possible to distinguish the different phases and to quantify $\mathrm{C}_{\mathrm{b}}(\mathrm{t})$.

The most challenging measurement faced by the complete model for calculating $\mathrm{CMRO}_{2}$ is to the experimental determination of $\mathrm{C}_{\mathrm{a}}(\mathrm{t})$, the concentration of $\mathrm{H}_{2}{ }^{17} \mathrm{O}$ in the feeding artery, especially when a small animal model is used. In order to accomplish this, we have designed an implanted ${ }^{17} \mathrm{O} R \mathrm{R}$ coil that permits the continuous measurement of $C_{a}(t)$ in a rat carotid artery [93]. This coil is based on a modified solenoid coil design combined with an RF shield. The RF shielding ensures that the NMR signal detected by the implanted coil originates only from the arterial blood $(\sim 7 \mu \mathrm{L})$ without contamination from surrounding tissues. Therefore, additional spatial localization was not necessary for determining $C_{a}(t)$. This setup allowed simultaneous measurements of both $\mathrm{C}_{\mathrm{a}}(\mathrm{t})$ and $\mathrm{C}_{\mathrm{b}}(\mathrm{t})$ using two independent coils and receiver channels with the same temporal resolution (11s). Fig. 8B illustrates the natural abundance $\mathrm{H}_{2}{ }^{17} \mathrm{O}$ spectrum detected from the blood in the rat carotid artery. Fig. 8C plots the results of simultaneous measurements of $\mathrm{C}_{\mathrm{a}}(\mathrm{t})$ change in one carotid artery and $\mathrm{C}_{\mathrm{b}}(\mathrm{t})$ change in a voxel located in the brain from the same rat during an inhalation of ${ }^{17} \mathrm{O}_{2}$. The results indeed demonstrate a linear relation between $\mathrm{C}_{\mathrm{a}}(\mathrm{t})$ and the inhalation time t. Fig. 8D demonstrates one example of $\mathrm{CMRO}_{2}$ calculation as a function of inhalation time from a single voxel in the rat brain from such an ${ }^{17} \mathrm{O}$ experiment. It is evident that the $\mathrm{CMRO}_{2}$ value is independent of the inhalation time if the initial two points are excluded, indicating that the tissue concentration of ${ }^{17} \mathrm{O}$ labeled oxygen molecule rapidly approaches the $\mathrm{K}_{m}$ of cytochrome Oxidase for oxygen after inhalation of ${ }^{17} \mathrm{O}$ gas commences.

The averaged $\mathrm{CMRO}_{2}$ and $\mathrm{CBF}$ values in the rat brain from seven measurements (five rats) were $2.19 \pm 0.14$ $\mu \mathrm{mol} / \mathrm{g} / \mathrm{min}$ and $0.53 \pm 0.07 \mathrm{ml} / \mathrm{g} / \mathrm{min}$, respectively, under conditions of $\alpha$-chloralose anesthesia [93].This is in excellent agreement with what can be calculated form an autoradiographic measurement [98] of cerebral metabolic rate of glucose $\left(\mathrm{CMR}_{\text {glc }}\right)(\sim 0.37 \mu$ mole/g/min $)$ using the $\mathrm{CMRO}_{2} /$ $\mathrm{CMR}_{\text {glc }}$ ratio of 5.5-6.0 [99]. In this autoradiographic study, both the anesthesia conditions and the CBF attained was similar to that in our own.

The $\mathrm{CMRO}_{2}$ measurements described in this chapter involve two invasive procedures, one for determining $C_{a}(t)$ by means of the implanted ${ }^{17} \mathrm{O}$ RF coil, the second for measuring $\mathrm{CBF}$ by an intra-arterial catheter and bolus injection of $\mathrm{H}_{2}{ }^{17} \mathrm{O}$. The CBF measurement can be performed noninvasively using the arterial spin tagging MR approaches. The use of the implanted RF coil, however, is not 

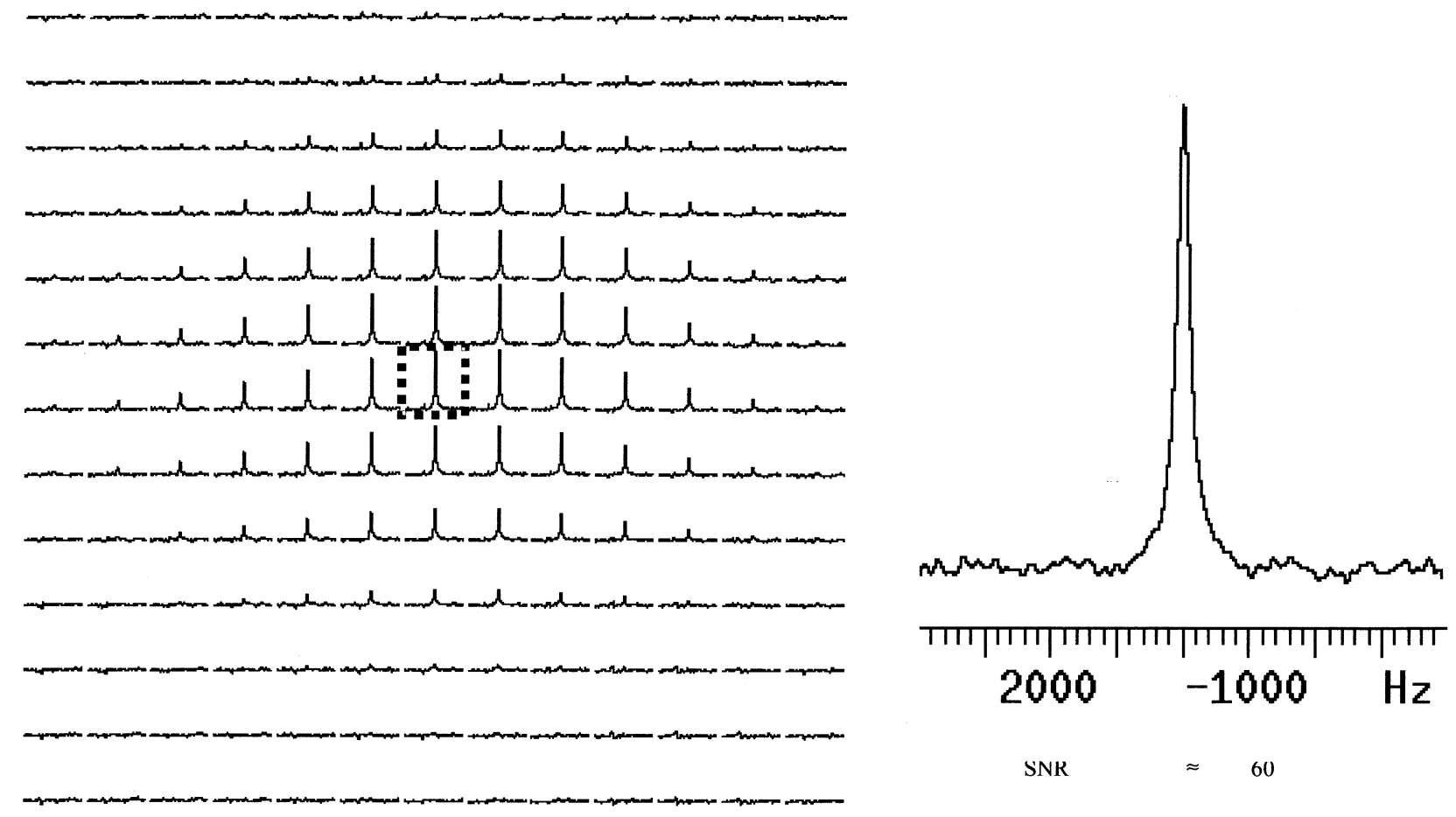

\section{(A)}

(B)

Fig. 9. A, ${ }^{17} \mathrm{OCSI}$ of natural abundance $\mathrm{H}_{2}{ }^{17} \mathrm{O}$ in the coronal orientation acquired from the human visual cortex at 7 Tesla. B, One representative ${ }^{17}$ Ospectrum from one central voxel as shown in A with $8.5 \mathrm{~s}$ of image acquisition time and $6.6 \mathrm{ml}$ voxel size.

suitable for routine measurements of $\mathrm{CMRO}_{2}$ using small experimental animal models (e.g, rat or mouse), or for human applications. Therefore, it is important to further explore the feasibility of the ${ }^{17} \mathrm{O}$ NMR approach for reliably imaging $\mathrm{CMRO}_{2}$ without resorting to invasive $\mathrm{C}_{\mathrm{a}}(\mathrm{t})$ and/or $\mathrm{CBF}$ measurements. Recently, we have investigated and showed this feasibility for imaging $\mathrm{CMRO}_{2}$ in the rat brain using simplified models, which only require noninvasive measurements of the cerebral $\mathrm{H}_{2}{ }^{17} \mathrm{O}$ concentration (i.e, $\mathrm{C}_{\mathrm{b}}(\mathrm{t})$ ), yielding similar $\mathrm{CMRO}_{2}$ results with that obtained using the complete model accounting for all parameters [100]. This work opens the possibility to establish a completely noninvasive ${ }^{17} \mathrm{O}$ NMR approach for $\mathrm{CMRO}_{2}$ imaging. However, this possibility needs further validations in different physiological conditions and species. This is, in particular, interesting and important for human applications, where elimination of invasive procedures is desirable if not absolutely necessary.

The success of high-field ${ }^{17} \mathrm{O}$ NMR for imaging $\mathrm{CMRO}_{2}$ in the human brain again relies on the ${ }^{17} \mathrm{O}$ NMR sensitivity. The sensitivity loss caused by the use of large RF coil size could be partially compensated by increasing image voxel size in the humans, which have a much large brain in comparison with most animals. Recently, we have studied the in vivo NMR sensitivity for acquiring 3-D ${ }^{17} \mathrm{O}$ images of natural abundance $\mathrm{H}_{2}{ }^{17} \mathrm{O}$ in the human visual cortex at 7
Tesla with a temporal resolution of $8.5 \mathrm{~s}$ and a voxel size of $6.6 \mathrm{ml}$. Fig. 9A demonstrates the results obtained from a representative subject showing one coronal ${ }^{17} \mathrm{O}$ CSI of natural abundance $\mathrm{H}_{2}{ }^{17} \mathrm{O}$ (extracted from 3-D ${ }^{17} \mathrm{O}$ CSI dataset). The CSI plane was located in the human visual cortex. Fig. 9B displays a representative ${ }^{17} \mathrm{O}$ spectrum from one central voxel showing the resonance peak of natural abundance $\mathrm{H}_{2}{ }^{17} \mathrm{O}$ in the human visual cortex and excellent SNR $(\approx 60: 1)$. This is better than that obtained from the rat brains at 9.4 Tesla $(\sim 40: 1)$ albeit with a larger absolute voxel size but not relative to the size of brain $[91,93]$. Furthermore, the dynamic concentration change of metabolic $\mathrm{H}_{2}{ }^{17} \mathrm{O}$ during an ${ }^{17} \mathrm{O}_{2}$ inhalation is expected to be similar between the awake human brain and the rat brain anesthetized with $\alpha$-chloralose because of similar values for both $\mathrm{CMRO}_{2}(2.2 \mu \mathrm{mol} / \mathrm{g} / \mathrm{min}$ in the anesthetized rat brain versus $1.7 \mu \mathrm{mol} / \mathrm{g} / \mathrm{min}$ in the awake human visual cortex) and $\mathrm{CBF}(0.53 \mathrm{ml} / \mathrm{g} / \mathrm{min}$ in the anesthetized rat brain versus $0.54 \mathrm{ml} / \mathrm{g} / \mathrm{min}$ in the awake human visual cortex) $[93,101]$. This comparison indicates that conditions in the rat brain in our studies and the awake human brain are comparable relative to the parameters that impact determination of $\mathrm{CMRO}_{2}$ from the ${ }^{17} \mathrm{O}$ data. Thus, it will be possible to achieve 3-D imaging of $\mathrm{CMRO}_{2}$ in the human brain at 7 Tesla or greater magnetic fields. Realization and utilization 


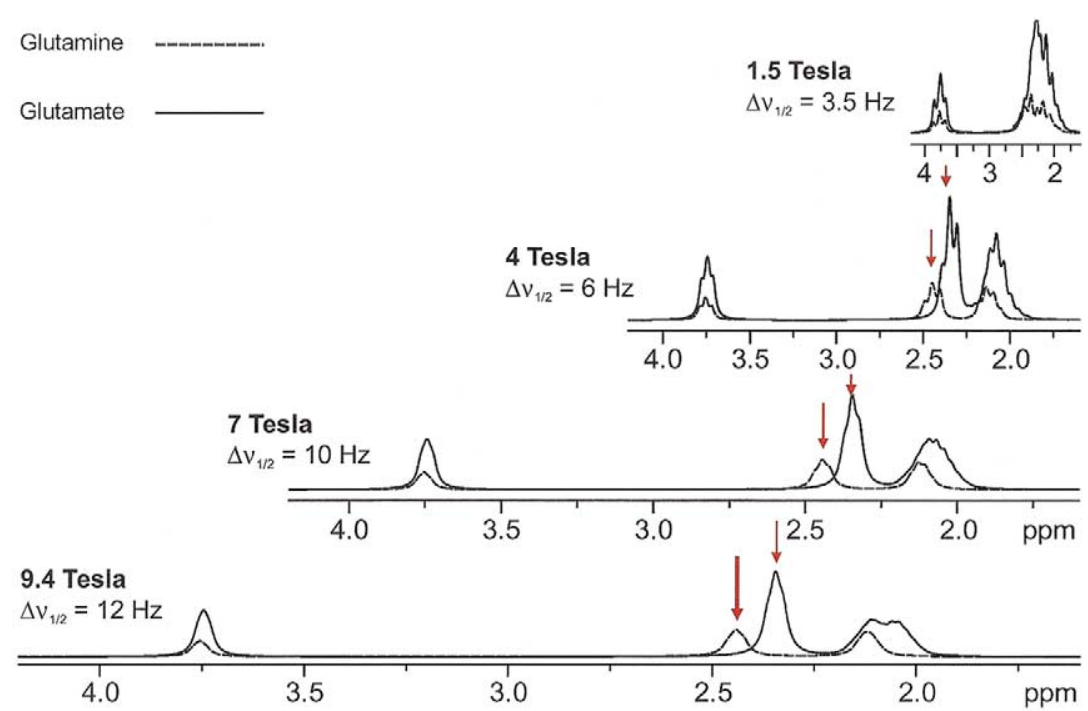

Fig. 10. Simulated ${ }^{1} \mathrm{H}$ spectrum of glutamate and glutamine at four different field strengths assuming that the line widths increase linearly with the magnetic field magnitude. Adapted from [103]

of this potential could have an important impact on studying bioenergetics in the human brain.

\section{Spectroscopy at high magnetic fields}

SNR gains somewhere between linear as observed for the ${ }^{1} \mathrm{H}$ spins and near quadratic as seen for ${ }^{17} \mathrm{O}$ nucleus will also be valid for spectroscopy studies that often utilize ${ }^{1} \mathrm{H}$, ${ }^{31} \mathrm{P},{ }^{13} \mathrm{C}$ nuclei. Spectroscopy studies with these nuclei, however, will also benefit significantly from unique advantages besides improved SNR at higher field strengths. Higher Bo fields yield improved resolution due to chemical shift and spectral simplifications of coupled spin systems.

In ${ }^{1} \mathrm{H}$ spectra obtained from the human brain, glutamate is resolved from glutamine partially at $4 \mathrm{~T}$ but not at $1.5 \mathrm{~T}$; these resonances are fully resolved at 9.4 Tesla [102]. For coupled spins, this resolution is attained even when the linewidths increase linearly with the magnetic field. This is because often the individual resonances of a multiplet are not resolved fully from each other in in vivo spectra and what is critical is the resolution of the entire multiplet from another multiplet. Even when the linewidths increase linearly with magnetic field, the effective width of the multiplet does not increase linearly because the splitting in the multiplet (i.e, J-coupling) is field independent. The resolution gained in this fashion is illustrated in Fig. 10 using simulation of glutamate and glutamine. The result of sensitivity and resolution gain is shown for human brain at 7 Tesla in Fig. 11.

An excellent example of the resolution afforded by high fields in ${ }^{1} \mathrm{H}$ spectroscopy is the detection of the $5.23 \mathrm{ppm}$ resonance of $\alpha$-glucose at $4 \mathrm{~T}$ (and higher fields) despite its proximity to $\mathrm{H}_{2} \mathrm{O}[102,103]$, providing for the first time the ability to measure cerebral glucose quantitatively by ${ }^{1} \mathrm{H}$
MRS without complications from overlapping resonances. All previous ${ }^{1} \mathrm{H}$ MRS studies concerned with MR detection of glucose at lower fields (e.g, [104-106]) have relied on the $3.4 \mathrm{ppm}$ peak of glucose which suffers from significant overlap from other resonances such as taurine in this very crowded region of the brain spectrum. As such, the $3.4 \mathrm{ppm}$ resonance cannot and should not be quantitatively used for measuring absolute glucose content in the human brain. The $5.23 \mathrm{ppm}$ peak of glucose, on the other hand, is isolated and does not suffer from overlap. However, this resonance is too close to the very large $\mathrm{H}_{2} \mathrm{O}$ peak to be detectable at the lower field strength because selective suppression of the latter without affecting the former has not been possible at the lower magnetic fields. The increased chemical shift resolution at $4 \mathrm{~T}$ or higher fields, however, permits selective suppression of the $\mathrm{H}_{2} \mathrm{O}$ resonance and detection of the 5.23 ppm peak of $\alpha$-glucose C1-H.

${ }^{31} \mathrm{P}$ NMR studies have been used both in animal models and in human studies to examine tissue bioenergetics, including the bioenergetics of increased neuronal activity. These studies have so far relied on detection of adenosine triphosphate (ATP), inorganic phosphate (Pi), phosphocreatine (PCr). Significant gains are realized at the higher fields for this nucleus as shown in Fig. 12. These data obtained with rats, document better than linear gains in SNR in spatially localized 31P spectra (Fig. 12); such gains permit investigations of bioenergetics in primate brain with greater accuracy and spatial resolution, and have been utilized in the human brain for evaluating pathology and brain activation [107]. Fig. 13 demonstrates ${ }^{31} \mathrm{P}$ spectra from the human brain at 7 Tesla. The SNR and chemical shift resolutuion available in this $7 \mathrm{~T}$ spectrum has not be attainable at lower fields and suggests that numerous experiments that have provided unique biochemical information at very high fields 


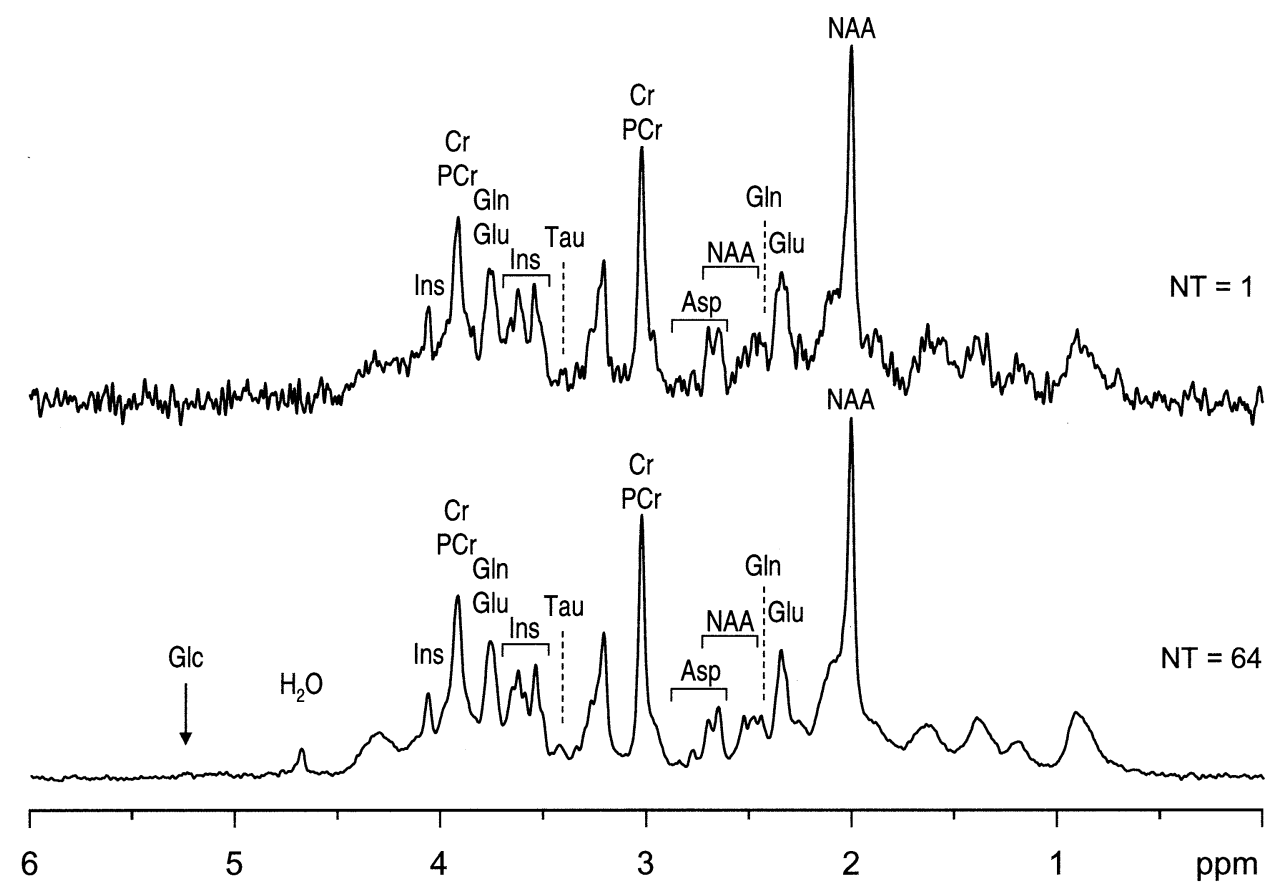

Fig. 11. ${ }^{1} \mathrm{H}$ NMR spectrum of the human brain at $7 \mathrm{~T}$ acquired over the occipital lobe, largely over gray matter, using STEAM (TE $=6 \mathrm{~ms}$, TR $=5 \mathrm{~s}$, VOI $=8 \mathrm{ml})$ for single shot $(\mathrm{N}=1)$ and for 64 averages.

but in animal models will also be feasible for human brain for the first time.

Spatially localized ${ }^{13} \mathrm{C}$ MRS has been employed to measure aspects of brain function and neurotransmission directly. Recent efforts have focused on understanding the coupling between cellular bioenergetics and neuronal activity (e.g, [108-115]). If ${ }^{13} \mathrm{C}$-enriched glucose is given to a living organism, the ${ }^{13} \mathrm{C}$ label is incorporated through metabolism into several positions in many different metabo- lites. Of interest is the incorporation of label into the intermediates of tricarboxylic acid (TCA) cycle, which generates reducing equivalents utilized in oxygen consumption. The label is then transferred into the amino acids glutamate, aspartate and glutamine. The ability to monitor the labeling of intracellular compounds in intact cells was first demonstrated using E. coli [116]. Today, such highly specific data can be obtained in human and animal brains from relatively small volume elements. Fig. 14 illustrates 9.4 Tesla spectra

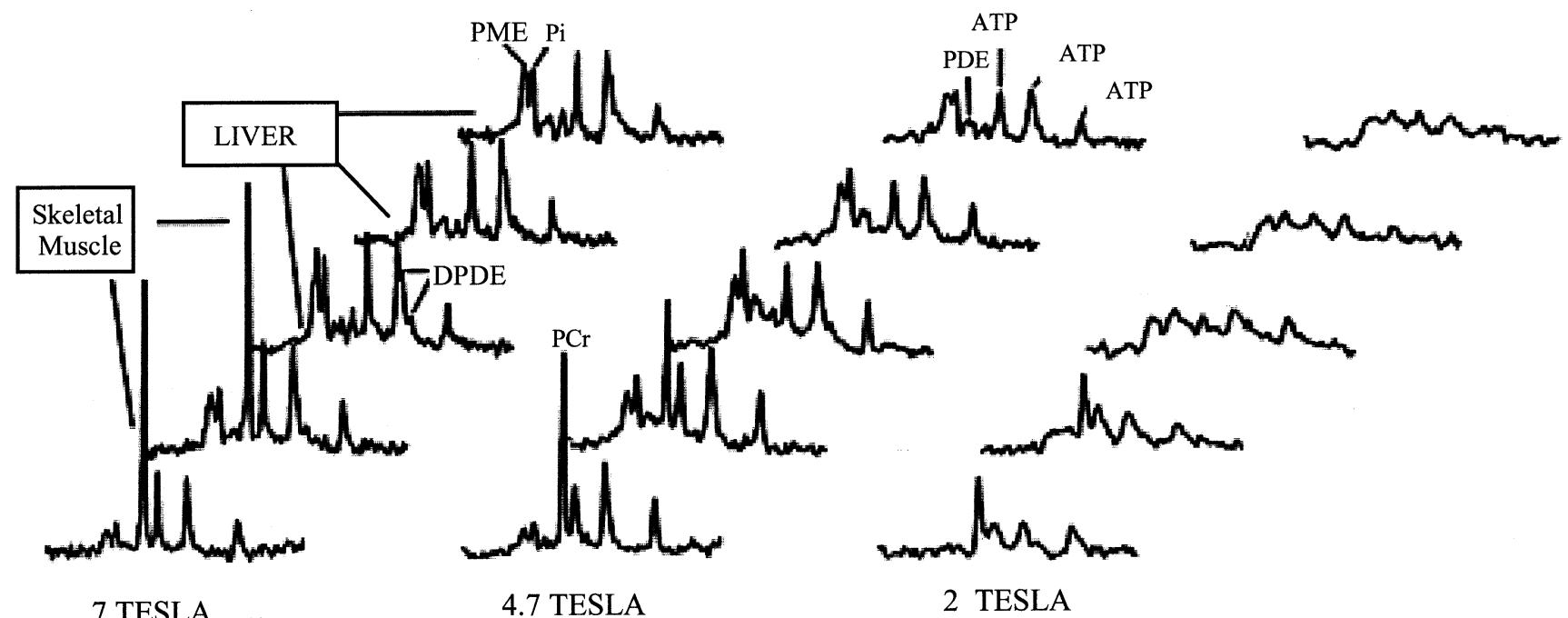

Fig. 12. 2, 4.7, 7 Tesla ${ }^{31} \mathrm{P}$ spectra acquired in five voxels over the abdomen of the same intact, reversibly anesthetized rat. These spectra were obtained using identical techniques, voxel volumes, number of scans, interpulse delay, identical total data acquisition time. Data provided by Dr. S. Weisdorf, M. Garwood, K. Hendrich, and K. Uğurbil. 

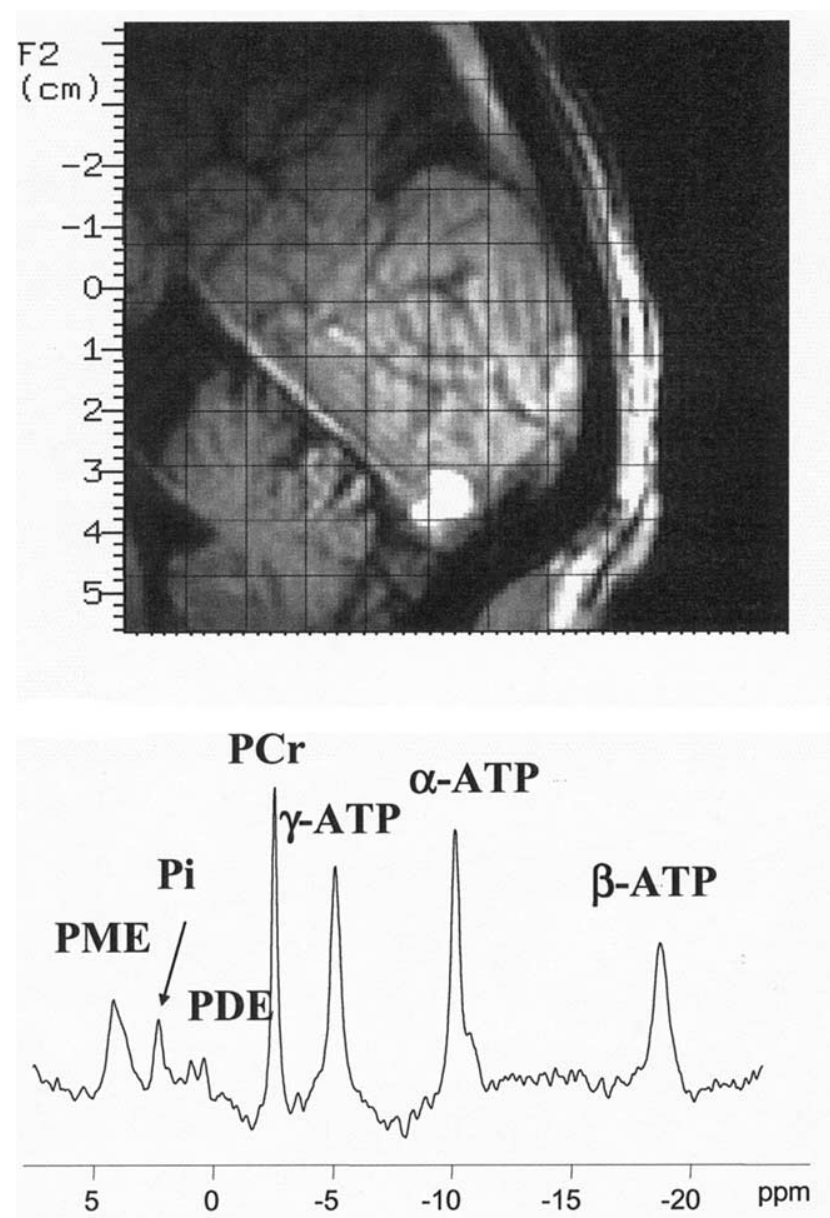

Fig. 13. 7 Tesla human brain ${ }^{31} \mathrm{P}$ MR spectra. Localized ${ }^{31} \mathrm{P}$ spectra were acquired with CSI (TR $=1.5 \mathrm{~s}$ and a $200 \mu$ s hard pulse for spin excitation). Spectra shown were acquired with 3-D CSI with a voxel size of $1.95 \mathrm{ml}$ and an acquisition time of $7.85 \mathrm{~min}$. Adapted from [124].

from the rat brain, before and after infusion of ${ }^{13} \mathrm{C}$ labeled glucose.

In the the human brain, ${ }^{13} \mathrm{C}$ spectra obtained at 4 Tesla in our laboratory illustrated the detection of many labeled compounds from a relatively small, localized region in the visual cortex, and allowed the first time measurement of neurotransmission rate in the human visual cortex [113]. A subsequent effort on humans at 2.1 Tesla [114] was able to report basically the same results, but used at least three-fold larger volumes ( $144 \mathrm{ml}$ vs. $45 \mathrm{ml})$ and longer data acquisition times for signal detection due to the lower field employed. In these studies, it is possible to extract information from the compartmentalized metabolic pathways. Most important is the glutamate-glutamine cycling between glia and the neurons, the two major cell types that are present in the brain: Glutamate is the major excitatory neurotransmitter. Once it is released into the synaptic cleft and binds the post-synaptic receptors during neurotransmission, it is scavenged rapidly by nearby glial processes $[117,118]$. Glutamate is then converted to glutamine by glutamine-synthase, which is present only in the glia [119]; glutamine is subse- quently transported to the neurons, converted to glutamate to replenish vesicular glutamate. Thus, glutamine labeling in ${ }^{13} \mathrm{C}$ experiments can in principle occur predominantly through glutamate release through neurotransmission and hence reflect the kinetics of neurotransmission. Therefore, from such ${ }^{13} \mathrm{C}$ studies, it is possible to calculate rates of glutamatergic neurotransmission, TCA cycle turnover, cerebral oxidative glucose utilization (CMRglu) and even break down the latter into glial and neuronal contributions. Most important finding from our studies is the conclusion that neurotransmission rate equals $\sim 60 \%$ of total oxidative glucose consumption rate in the awake human brain and that there is significant oxidative ATP production rate in the glia, apparently in contradiction with earlier conclusions reached from experiments on the anesthetized rat brain data [120].

Such detailed studies have not yet been applied to investigate neuronal activation in the human or animal brains due to limitations in signal-to-noise ratio of the measurements. However, a subset of the data in the direct ${ }^{13} \mathrm{C}$ measurements can be acquired with indirect detection with higher sensitivity using the protons attached to the ${ }^{13} \mathrm{C}$ nuclei, permitting calculations of changes in TCA cycle turnover and oxidative CMRglu during neuronal activation. Such an experiment was performed at 4 Tesla using hemifield visual stimulation. Spectroscopic data during ${ }^{13} \mathrm{C}$ infusion was used to obtain glutamate labeling kinetics together with CBF and BOLD fMRI from an activated region in one hemisphere while the other hemisphere served as control [108]. Hemifield visual stimulation selectively activates the primary visual cortex of the contralateral hemisphere, thus approximately half the primary visual cortex volume that normally would be engaged during full field stimulation. Spectra were acquired from two volumes positioned so that only one of the two covers the "activated" region within one hemisphere while the other covers the analogous but nonactivated region within the other hemisphere. These data put an upper limit on the increase in $\mathrm{CMRO}_{2}$ of $30 \%$ as opposed to larger increases in $\mathrm{CBF}$, supporting the concept that $\mathrm{CMRO}^{2}$ is not stochiometrically coupled to increases in CBF and CMRglu. This measurement is significant because of the controversy surrounding the coupling of oxidative metabolism and neuronal activity. It is well known that under resting conditions, the cerebral metabolic rate of glucose consumption is well coupled to $\mathrm{CMRO}_{2}$ as well as to cerebral blood flow in the human brain ([121] and references therein), the glucose metabolism is almost completely through oxidation. However, this appears not to be the case during increased neuronal activity. Based on PET studies, the increases of CMRO2 (0-5\%) were found to be much less than the elevation in CBF and CMRglc (40-51\%) during visual and somatosensory stimulations [27,122]. This early PET result remains to this day highly debated, with the intensity of debate having increased recently in view of its significance in understanding the BOLD response that has come to play such a prominent role in neuroscience research. The difficulties and complexities as- 


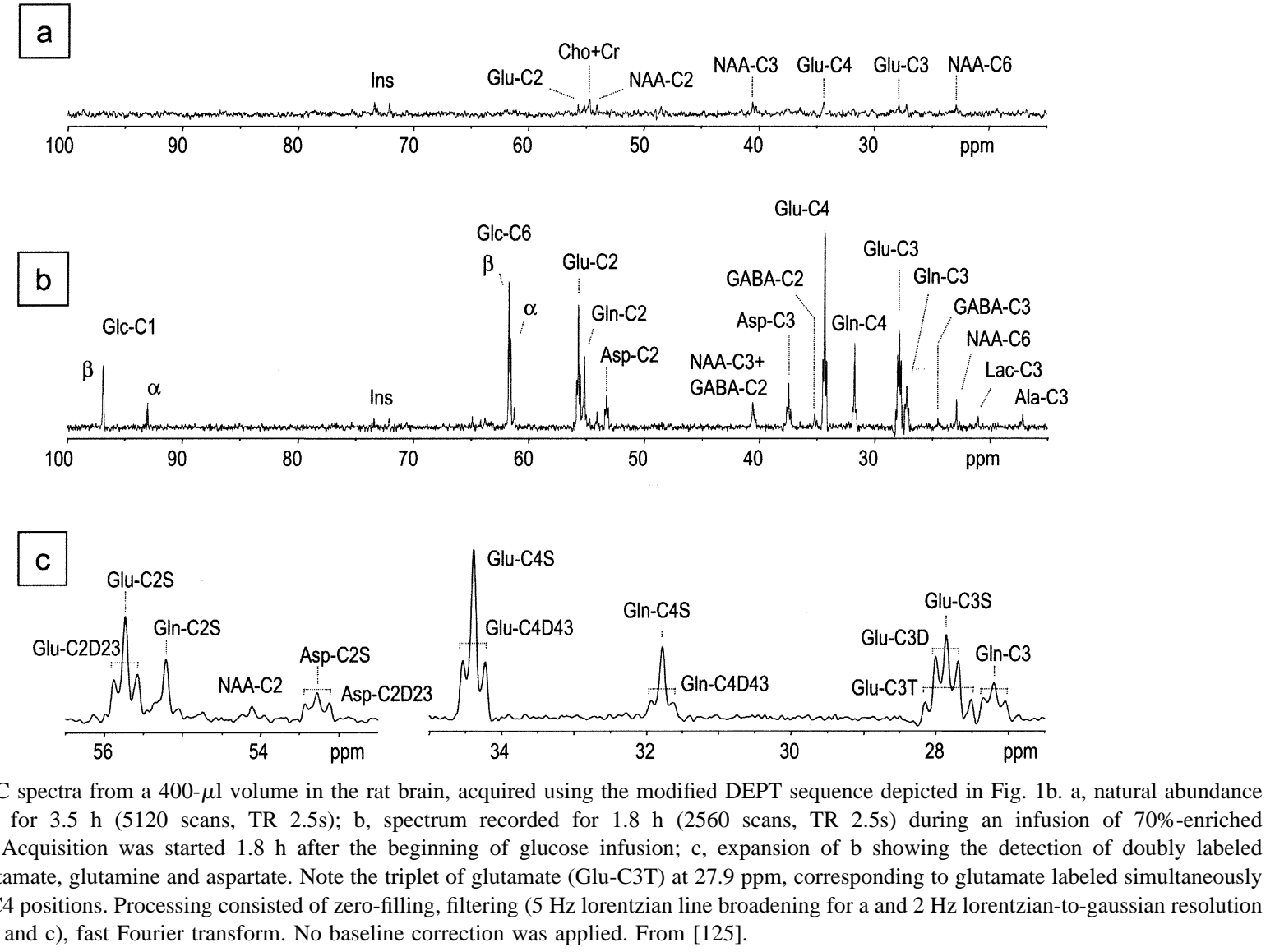

sociated with PET measurement of $\mathrm{CMRO}_{2}$ have also led to skepticism about the validity of the data that generated this controversial concept. The spectroscopic data support the concept that during increased neuronal activity, the fractional increase in CBF significantly exceeds the fractional increase in $\mathrm{CMRO}_{2}$ and by implication $\mathrm{CMR}_{\text {glu }}$ which appears to track the changes in $\mathrm{CBF}$.

\section{Conclusion}

Very high magnetic fields (4 Tesla and above) have been used in human biomedical research only recently and in only few groups. The results so far suggest that while indeed technical challenges increase substantially, there are also significant gains that can be realized in many applications ranging from proton imaging to spectroscopy.

\section{Acknowledgments}

The work reported here from the Center for Magnetic Resonance Research, University of Minnesota, was supported by the National Research Resources (NCRR) division of the National Institutes of Health Grant P41 RR08079.

\section{References}

[1] Ogawa S, Tank DW, Menon R, Ellermann JM, Kim SG, Merkle H, Ugurbil K. Intrinsic signal changes accompanying sensory stimulation: functional brain mapping with magnetic resonance imaging. Proc Natl Acad Sci USA 1992;89:5951-5.

[2] Kwong KK, Belliveau JW, Chesler DA, et al. Dynamic magnetic resonance imaging of human brain activity during primary sensory stimulation. Proc Natl Acad Sci USA 1992;89:5675-9.

[3] Hoult DI, Richards RE. The signal-to-noise ratio of the nuclear magnetic resonance phenomenon. J Magn Reson 1976;24:71-85.

[4] Hoult DI, Lauterbur PC. The sensitivity of the zeugmatographic experiment involving human samples. J Magn Reson 1979;34:42533.

[5] Wen H, Chesnick AS, Balaban RS. The design and test of a new volume coil for high field imaging. Magn Reson Med 1994;32: 492-8.

[6] Hoult DI, Phil D. Sensitivity and power deposition in a high-field imaging experiment. J Magn Reson Imaging, 2000;12:46-67.

[7] Keltner JR, Carlson JW, Roos MS, Wong STS, Wong TL, Budinger TF. Electromagnetic fields of surface coil in vivo NMR at high frequencies. Magn Reson Med 1991;22:46-480.

[8] Vesselle $\mathrm{H}$, Collin RE. The signal-to-noise ratio of nuclear magnetic resonance surface coils and application to lossy dielectric cylinder model. Part II: the case of cylinderical window studies. IEEE Trans Biomed Eng 1995;42:507-20.

[9] Vesselle H, Collin RE. The signal-to-noise ratio of nuclear magnetic resonance surface coils and application to lossy dielectric cylinder model. Part I: theory. IEEE Trans Biomed Eng 1995;42:497-505. 
[10] Gati JS, Menon RS, Ugurbil K, Rutt BK. Experimental determination of the BOLD field strength dependence in vessels and tissue. Magn Reson Med 1997;38:296-302.

[11] Vaughan JT, Garwood M, Collins CM, et al. 7 T vs. 4 T: RF power, homogeneity, signal-to-noise comparison in head images. Magn Reson Med 2001;46:24-30.

[12] Pfeuffer J, Van de Moortele PF, Yacoub E, Shmuel A, Adriany G, Andersen P, Merkle H, Garwood M, Urgurbil K, Hu X. Zoomed functional imaging in the human brain at 7 Tesla with simultaneous high spatial and high temporal resolution. Neuroimage 2002;17: $272-86$.

[13] Pfeuffer J, Adriany G, Shmuel A, Yacoub E, Van de Moortele PF, $\mathrm{Hu} X$, Urgurbil K. Perfusion-based high-resolution functional imaging in the human brain at 7 Tesla. Magn Reson Med 2002;47: 903-11.

[14] Yacoub E, Duong TQ, Van de Moortele PF, Lindquist M, Adriany G, Kim SG, Urgurbil K, Hu X. Spin-echo fMRI in humans using high spatial resolutions and high magnetic fields. Magn Reson Med 2003;49:655-64.

[15] Kim S-G, Hu X, Urgurbil K. Accurate $T_{1}$ determination from inversion recovery images: application to human brain at 4 tesla. Magn Reson Med 1994;31:445-9.

[16] Jezzard P, Duewell S, Balaban RS. MR relaxation times in human brain: measurement at 4 T. Radiology 1996;199:773-9.

[17] Ugurbil K, Garwood M, Ellermann J, Hendrich K, Hinke R, Hu X, Kim SG, Menon R, Merkle H, Ogawa S, et al. Imaging at high magnetic fields: initial experiences at 4 T. Magn Reson Q 1993;9: 259-77.

[18] Lee JH, Garwood M, Menon R, Adriany G, Andersen P, Truwit CL, Urgurbil K. High contrast and fast three-dimensional magnetic resonance imaging at high fields. Magn Reson Med 1995;34:308-12.

[19] Vaughan JT, Garwood M, Collins CM, DelaBarre L, Adriany G, Andersen P, Merkle H, Smith MB, Urgurbil K. 7 T vs 4 T: preliminary B1, SNR, SAR comparison in the human head. In: 8th Annual Scientific Meeting of the International Society of Magnetic Resonance in Medicine. 2000. Denver, CO.

[20] Vaughan JT, Hetherington HP, Otu JO, Pan JW, Pohost GM. High frequency volume coils for clinical NMR imaging and spectroscopy. Magn Reson Med 1994;32:206-18.

[21] Pan JW, Vaughan JT, Kuzniecky RI, Pohost GM, Hetherington HP. High resolution neuroimaging at 4.1T. Magn Reson Imaging 1995; 13:915-21.

[22] Robitaille PM, Abduljalil AM, Kangarlu A. Ultra high resolution imaging of the human head at 8 tesla: $2 \mathrm{~K} \times 2 \mathrm{~K}$ for $\mathrm{Y} 2 \mathrm{~K}$. J Comput Assist Tomogr 2000;24:2-8.

[23] Kangarlu A, Abduljalil AM, Robitaille PM. T1- and T2-weighted imaging at 8 Tesla. J Comput Assist Tomogr 1999;23:875-8.

[24] Christoforidis GA, Bourekas EC, Baujan M, Abduljalil AM, Kangarlu A, Spigos DG, Chakeres DW, Robitaille PM. High resolution MRI of the deep brain vascular anatomy at 8 Tesla: susceptibilitybased enhancement of the venous structures. J Comput Assist Tomogr 1999;23:857-66.

[25] Burgess RE, Yu Y, Abduljalil AM, Kangarlu A, Robitaille PM. High signal-to-noise FLASH imaging at 8 Tesla. Magn Reson Imaging 1999;17:1099-103.

[26] Bandettini PA, Wong EC, Hinks RS, Tikofsky RS, Hyde JS. Time course EPI of human brain function during task activation. Magn Reson Med 1992;25:390-7.

[27] Fox PT, Raichle ME, Mintun MA, Dence C. Nonoxidative glucose consumption during focal physiologic neural activity. Science 1988; 241:462-4.

[28] Shmuel A, Yacoub E, Pfeuffer J, Van de Moortele PF, Adriany G, $\mathrm{Hu} \mathrm{X}$, Urgurbil K. Sustained negative BOLD, blood flow and oxygen consumption response and its coupling to the positive response in the human brain. Neuron 2002;36:1195-210.
[29] Pfeuffer J, McCullough JC, Van de Moortele PF, Urgurbil K, Hu X. Spatial dependence of the nonlinear BOLD response at short stimulus duration. Neuroimage 2003;18:990-1000.

[30] Yacoub E, Shmuel A, Pfeuffer J, Van de Moortele PF, Adriany G, Andersen P, Vaughan JT, Merkle H, Urgurbil K, Hu X. Imaging brain function in humans at 7 Tesla. Magn Reson Med 2001;45: $588-94$.

[31] Yacoub E, Shmuel A, Pfeuffer J, Van de Moortele PF, Adriany G, Urgurbil K, Hu X. Investigation of the initial dip in fMRI at 7 Tesla. NMR Biomed, 2001;14:408-12.

[32] Silva AC, Koretsky AP. Laminar specificity of functional MRI onset times during somatosensory stimulation in rat. Proc Natl Acad Sci USA 2002;99:15182-7.

[33] Sereno MI, Dale AM, Reppas JB, Kwong KB, Belliveau JW, Brady TJ, Rosen BR, Tootell RBH. Borders of multiple visual areas in humans revealed by functional magnetic resonance imaging. Science 1995;268:889-93.

[34] DeYoe EA, Carman GJ, Bandettini P, Glickman S, Wieser J, Cox R, Miller D, Neitz J. Mapping striate and extrastriate visual areas in human cerebral cortex. Proc Natl Acad Sci USA 1996;93:2382-6.

[35] Engel SA, Glover GH, Wandell BA. Retinotopic organization in human visual cortex and the spatial precision of functional MRI. Cereb Cortex 1997;7:181-92.

[36] Duong QD, Kim D-S, Urgurbil K, K. S-G Spatio-temporal dynamics of BOLD fMRI signals: towards mapping submillimeter cortical columns using the early negative response. Magn Reson Med 2000; 44:231-42.

[37] Kim DS, Duong TQ, Kim SG. High-resolution mapping of isoorientation columns by fMRI. Nat Neurosci 2000;3:164-9.

[38] Toth LJ, Ronen I, Olman C, Urgurbil K, Kim D-S. Spatial correlation of BOLD activity with neuronal responses. Soc. Neurosci. Abstracts. 2001.

[39] Ugurbil K, Toth L, Kim DS. How accurate is magnetic resonance imaging of brain function? Trends Neurosci 2003;26:108-14.

[40] Dechent P, Frahm J. Direct mapping of ocular dominance columns in human primary visual cortex. Neuroreport 2000;11:3247-9.

[41] Menon RS, Goodyear BG. Submillimeter functional localization in human striate cortex using BOLD contrast at 4 Tesla: implications for the vascular point-spread function. Magn Reson Med 1999;41: $230-5$.

[42] Menon RS, Ogawa S, Strupp JP, Urgurbil K. Ocular dominance in human V1 demonstrated by functional magnetic resonance imaging. J Neurophysiol 1997;77:2780-7.

[43] Goodyear BG, Menon RS. Brief visual stimulation allows mapping of ocular dominance in visual cortex using fMRI. Hum Brain Mapp 2001;14:210-7.

[44] Cheng K, Waggoner RA, Tanaka K. Human ocular dominance columns as revealed by high-field functional magnetic resonance imaging. Neuron, 2001;32:359-74.

[45] Menon RS, Ogawa S, Tank DW, Urgurbil K. 4 Tesla gradient recalled echo characteristics of photic stimulation- induced signal changes in the human primary visual cortex. Magn Reson Med 1993;30:380-6.

[46] Detre JA, Leigh JS, Williams DS, Koretsky AP. Perfusion imaging. Magn Reson Med 1992;23:37-45.

[47] Detre JA, Zhang W, Roberts DA, Silva AC, Williams DS, Grandis DJ, Koretsky AP, Leigh JS. Tissue specific perfusion imaging using arterial spin labeling. NMR Biomed 1994;7:75-82.

[48] Barbier EL, Silva AC, Kim HJ, Williams DS, Koretsky AP. Perfusion analysis using dynamic arterial spin labeling (DASL). Magn Reson Med 1999;41:299-308.

[49] Barbier EL, Silva AC, Kim SG, Koretsky AP. Perfusion imaging using dynamic arterial spin labeling (DASL). Magn Reson Med 2001;45:1021-9.

[50] Edelman RE, Siewer B, Darby DG, Thangaraj V, Nobre AC, Mesulam MM, Warach S. Quantitative mapping of cerebral blood flow and functional localization with echo-planar MR imaging and signal 
targeting with alternating radio frequency. Radiology 1994;192: 513-20.

[51] Wong EC, Buxton RB, Frank LR. Quantitative imaging of perfusion using a single subtraction (QUIPSS and QUIPSS II). Magn Reson Med 1998;39:702-8.

[52] Iadecola CG, Yang G, Ebner TJ, Chen G. Local and propagated vascular responses evoked by focal synaptic activity in cerebellar cortex. J Neurophysiol 1997;78:651-9.

[53] Tsekos NV, Zhang F, Merkle H, Nagayama M, Iadecola C, Kim SG. Quantitative measurements of cerebral blood flow in rats using the FAIR technique: correlation with previous iodoantipyrine autoradiographic studies. Magn Reson Med 1998;39:564-73.

[54] Lee S-P, Silva AC, Urgurbil K, K S-G. Diffusion-weighted spin echo fMRI at $9.4 \mathrm{~T}$ : microvascular/tissue contribution to BOLD signal changes. Mag Reson Med 1999:42; 919-28.

[55] Duong TQ, Yacoub E, Adriany G, Hu X, Urgurbil K, Kim SG. Microvascular BOLD contribution at 4 and $7 \mathrm{~T}$ in the human brain: gradient-echo and spin-echo fMRI with suppression of blood effects. Magn Reson Med 2003;49:1019-27.

[56] Duong TQ, Silva AC, Lee SP, Kim SG. Functional MRI of calciumdependent synaptic activity: cross correlation with CBF and BOLD measurements. Magn Reson Med 2000;43:383-92.

[57] Lin YJ, Koretsky AP. Manganese ion enhances T1-weighted MRI during brain activation: an approach to direct imaging of brain function. Magn Reson Med 1997;38:378-88.

[58] Duong TQ, Kim DS, Urgurbil K, Kim SG. Localized cerebral blood flow response at submillimeter columnar resolution. Proc Natl Acad Sci USA 2001;98:10904-9.

[59] Grubb RL, Raichle ME, Eichling JO, Ter-Pogossian MM. The effects of changes in $\mathrm{PaCO} 2$ on cerebral blood volume, blood flow, vascular mean transit time. Stroke 1974;5:630-9.

[60] Grinvald A., Vanzetta I. Personal communications. 2003.

[61] Ugurbil K, Hu X, Chen W, Zhu X-H, Kim S-G, Georgopoulos A. Functional mapping in the human brain using high magnetic fields. Philos Trans R Soc Lond B Biol Sci 1999;354:1195-213.

[62] Ugurbil K, Ogawa S, Kim S-G, Hu X, Chen W, Zhu X-H. Imaging brain activity using nuclear spins. In: Maraviglia B, editor. Magnetic resonance and brain function. Amsterdam: Societa Italiana di Fisica and IOS Press, 1999. p. 261-301.

[63] Ugurbil K, Adriany G, Andersen P, Chen W, Gruetter R, Hu X, Merkle H, Kim DS, Kim SG, Strupp J, Zhu XH, Ogawa S. Magnetic resonance studies of brain function and neurochemistry. Annu Rev Biomed Eng 2000;2:633-60.

[64] Ogawa S, Menon RS, Kim SG, Urgurbil K. On the characteristics of functional magnetic resonance imaging of the brain. Annu Rev Biophys Biomol Struct 1998;27:447-74.

[65] van Zijl PC, Eleff SM, Ulatowski JA, Oja JM, Ulug AM, Traystman RJ, Kauppinen RA. Quantitative assessment of blood flow, blood volume and blood oxygenation effects in functional magnetic resonance imaging [see comments]. Nat Med 1998;4:159-67.

[66] Pawlik G, Rackl A, Bing RJ. Quantitative capillary topography and blood flow in the cerebral cortex of cats: an in vivo microscopic study. Brain Res 1981;208:35-58.

[67] Thulborn KR, Waterton JC, Matthews PM. Dependence of the transverse relaxation time of water protons in whole blood at high field. Biochem Biophys Acta 1992;714:265-272.

[68] Barth M, Moser E. Proton NMR relaxation times of human blood samples at $1.5 \mathrm{~T}$ and implications for functional MRI. Cell Mol Biol (Noisy-le-grand) 1997;43:783-91.

[69] Mildner T, Norris DG, Schwarzbauer C, Wiggins CJ. A qualitative test of the balloon model for BOLD-based MR signal changes at 3T. Magn Reson Med 2001;46:891-9.

[70] Wong-Riley M, Anderson B, Liebl W, Huang W. Neurochemical organization of the macaque striate cortex: correlation of cytochrome oxidase with $\mathrm{Na}^{+} \mathrm{K}^{+}$ATPase, NADPH-diaphorase, nitric oxide synthase, $N$-methyl-D-aspartate receptor subunit 1 . Neuroscience 1998;83:1025-45.
[71] Ronen I, Lee JH, Merkle H, Urgurbil K, Navon G. Imaging H2(17)O distribution in a phantom and measurement of metabolically produced H2(17)O in live mice by proton NMR. NMR Biomed 1997; 10:333-40.

[72] Zhu XH, Merkle H, Kwag JH, Urgurbil K, Chen W. 17 O relaxation time and NMR sensitivity of cerebral water and their field dependence. Magn Reson Med 2001;45:543-9.

[73] Zhu XH, Zhang Y, Tian RX, Lei H, Zhang N, Zhang X, Merkle H, Urgurbil K, Chen W. Development of (17)O NMR approach for fast imaging of cerebral metabolic rate of oxygen in rat brain at high field. Proc Natl Acad Sci USA 2002;99:13194-9.

[74] Grinvald A, Frostig RD, Siegel RM, Bartfeld E. High-resolution optical imaging of functional brain architecture in the awake monkey. Proc Natl Acad Sci USA 1991;88:11559-63.

[75] Venzetta I, Grinvald A. Phosphorescence decay measurements in cat visual cortex show early blood oxygenation level decrease in response to visual stimulation,. Neurosci Lett 1998;51(Suppl):S42.

[76] Vanzetta I, Grinvald A. Increased cortical oxidative metabolism due to sensory stimulation: implications for functional brain imaging. Science 1999;286:1555-8.

[77] Malonek D, Dirnagl U, Lindauer U, Yamada K, Kanno I, Grinvald A. Vascular imprints of neuronal activity: relationships between the dynamics of cortical blood flow, oxygenation, volume changes following sensory stimulation. Proc Natl Acad Sci USA 1997;94: $14826-31$

[78] Grinvald A, Slovin H, Vanzetta I. Non-invasive visualization of cortical columns by fMRI. Nat Neuroscience 2000;3:105-7.

[79] Hu X, Le TH, Urgurbil K. Evaluation of the early response in fMRI using short stimulus duration. Magn Reson Med 1997;37:877-84.

[80] Menon RS, Ogawa S, Hu X, Strupp JP, Anderson P, Urgurbil K. BOLD based functional MRI at 4 Tesla includes a capillary bed contribution: echo-planar imaging correlates with previous optical imaging using intrinsic signals. Magn Reson Med 1995;33:453-9.

[81] Twieg DB, Moore GG, Zhang YT. Estimating fast response onset time. In: International Society of Magnetic Resonance in Medicine. 5th Scientific Meeting. 1997. Vancouver, British Columbia, Canada.

[82] Yacoub E, Le TH, Urgurbil K, Hu X. Further evaluation of the initial negative response in functional magnetic resonance imaging. Magn Reson Med 1999;41:436-41.

[83] Yacoub E, Vaughn T, Adriany G, Andersen P, Merkle H, Urgurbil $\mathrm{K}, \mathrm{Hu} \mathrm{X}$. Observation of the initial "dip" in fMR1 signal in human visual cortex at 7 Tesla. Proc Intl Soc Magn Reson Med 2000;8:991.

[84] Cannestra AF, Pouratian N, Bookheimer SY, Martin NA, Beckerand DP, Toga AW. Temporal spatial differences observed by functional MRI and human intraoperative optical imaging. Cereb Cortex 2001; 11:773-82.

[85] Logothetis NK, Gugenberger H, Peled S, Pauls J. Functional imaging of the monkey brain. Nature Neurosci 1999;2:555-60.

[86] Hoult DI, Richards RE. The signal-to-noise ratio of nuclear magnetic resonance experiment. J Magn Reson 1976;24:71-85.

[87] Wen H, Chesnick AS, Balaban RS. The design and test of a new volume coil for high field imaging. Magn Reson Med 1994;32: 492-8.

[88] Abragam A. The principles of nuclear magnetism. In: Mott NF, Bullard EC, Wilkinson DH, editors. The international series of monographs on physics. London: Oxford University Press, 1961.

[89] Steinhoff HJ, Kramm B, Hess G, Owerdieck C, Redhardt A. Rotational and translational water diffusion in the hemoglobin hydration shell: dielectric and proton nuclear relaxation measurements. Biophys J 1993;65:1486-95.

[90] Meiboom S. NMR study of the proton transfer in water. J Chem Phys 1961;34:375-88.

[91] Zhu XH, Merkle H, Kwag JH, Urgurbil K, Chen W. ${ }^{17}$ O relaxation time and NMR sensitivity of cerebral water and their field dependence. Magn Reson Med 2001;45:543-9.

[92] Pekar J, Sinnwell T, Ligeti L, Chesnick AS, Frank JS, McLaughlin AC. Simultaneous measurement of cerebral oxygen consumption 
and blood flow using ${ }^{17} \mathrm{O}$ and ${ }^{19} \mathrm{~F}$ magnetic resonance imaging. J Cereb Blood Flow Metab 1995;15:312-20.

[93] Zhu XH, Zhang Y, Tian TX, Lei H, Zhang N, Zhang X, Merkle H, Urgurbil K, Chen W. Development of 17O NMR approach for fast imaging of cerebral metabolic rate of oxygen in rat brain at high field. Proc Natl Acad Sci USA 2002;99:13194-9.

[94] Herscovitch A, Raichle ME. What is the correct value for the brain-blood partition coefficient for water? J Cereb Blood Flow Metab 1985;5:65-9.

[95] Herscovitch P, Raichle ME, Kilbourn MR, Welch MJ. Positron emission tomographic measurement of cerebral blood flow and permeability-surface area product of water using [15O]water and [11C]butanol. J Cereb Blood Flow Metab 1987;7:527-42.

[96] Zhu XH, Lei H, Zhang Y, Zhang XL, Zhang N, Urgurbil K, Chen $\mathrm{W}$. Evidence of limited permeation of metabolic water in rat brain observed by ${ }^{17} \mathrm{O}$ magnetic resonance spectroscopic imaging and its implications. In: 10th Annual Meeting of International Society for Magnetic Resonance in Medicine. 2002. Hawaii.

[97] Lee SP, Silva AC, Urgurbil K, Kim SG. Diffusion-weighted spinecho fMRI at $9.4 \mathrm{~T}$ : microvascular/tissue contribution to BOLD signal changes. Magn Reson Med 1999;42:919-28.

[98] Nakao YY, Itoh TY, Kuang M, Cook J, Jehle J, Sokoloff L. Effects of anesthesia on functional activation of cerebral blood flow and metabolism. Proc Natl Acad Sci USA 2001;98:7593-8.

[99] Siesjo BK. Brain energy metabolism. New York: Wiley, 1978. p. 101-10.

[100] Zhang NY, Zhu XH, Lei H, Urgurbil K, Chen W. Calculation of cerebral metabolic rate of oxygen based on ${ }^{17} \mathrm{O}$ MRS imaging with 2 min ${ }^{17} \mathrm{O}_{2}$ Inhalation: a simplified approach. In: 10th Annual Meeting of International Society for Magnetic Resonance in Medicine. 2002. Hawaii.

[101] Fox PT, Raichle ME, Mintun MA, Dence C. Nonoxidative glucose consumption during focal physiologic neural activity. Science 1988; 241:462-4

[102] Gruetter R, Garwood M, Urgurbil K, Seaquist ER. Observation of resolved glucose signals in $1 \mathrm{H}$ NMR spectra of the human brain at 4 Tesla. Magn Reson Med 1996;36:1-6.

[103] Tkac I, Andersen P, Adriany G, Merkle H, Urgurbil K, Gruetter R. In vivo (1)H NMR spectroscopy of the human brain at $7 \mathrm{~T}$. Magn Reson Med, 2001;46:451-6.

[104] Chen W, Novotny E, Zhu XH, Rothman D, Shulman RG. Localized $1 \mathrm{H}$ NMR measurement of glucose consumption in human brain during visual stimulation. Proc Natl Acad Sci USA 1993;90:9896900.

[105] Frahm J, Kruger KD, Merboldt KD, Kleinschmidt A. Dynamic uncoupling and recoupling of perfusion and oxidative metabolism during focal brain activation in man. Magn Reson Med 1996;35: $143-8$.

[106] Merboldt KD, Bruhn H, Hanicke W, Michaelis T, Frahm J. Decrease of glucose in the human visual cortex during photic stimulation. Magn Reson Med 1992;25:187-94.

[107] Chen W, Zhu XH, Adriany G, Urgurbil K. Increase of creatine kinase activity in the visual cortex of human brain during visual stimulation: a 31P magnetization transfer study. Magn Reson Med 1997;38:551-7.

[108] Chen W, Zhu XH, Gruetter R, Seaquist ER, Adriany G, Urgurbil K. Study of tricarboxylic acid cycle flux changes in human visual cortex during hemifield visual stimulation using (1)H-\{(13)C $\}$ MRS and fMRI. Magn Reson Med 2001;45:349-55.

[109] Hyder F, Chase JR, Behar KL, Mason GF, Siddeek M, Rothman DL, Shulman RG. Increased tricarboxylic acid cycle flux in rat brain during forepaw stimulation detected with $1 \mathrm{H}[13 \mathrm{C}] \mathrm{NMR}$. Proc Natl Acad Sci USA 1996;93:7612-7.

[110] Hyder F, Rothman DL, Mason GF, Rangarajan A, Behar KL, Shulman RG. Oxidative glucose metabolism in rat brain during single forepaw stimulation: a spatially localized $1 \mathrm{H}[13 \mathrm{C}]$ nuclear magnetic resonance study. J Cereb Blood Flow Metab 1997;17:1040-7.

[111] Gruetter R, Novotny EJ, Boulware SD, GF M, Rothman DL, Prichard JW, RG S. Localized 13C NMR spectroscopy of amino acid labeling from [1-13C] D-glucose in the human brain. J Neurochem 1994;63:1377-85.

[112] Sibson NR, Dhankhar A, Mason GF, Behar KL, Rothman JW, Shulman RG. In vivo 13C NMR measurements of cerebral glutamine synthesis as evidence for glutamate-glutamine cycling. Proc Natl Acad Sci USA 1997;94:2699-704.

[113] Gruetter R, Seaquest ER, Kim SW, Urgurbil K. Localized in vivo 13C NMR of glutamate metabolism in the human brain. Initial results at 4 Tesla. Dev Neurosci 1998;20:380-8.

[114] Shen J, Petersen KF, Behar KL, Brown P, Nixon TW, Mason GF, Petroff OA, Shulman GI, Shulman RG, Rothman DL. Determination of the rate of the glutamate/glutamine cycle in the human brain by in vivo 13C NMR. Proc Natl Acad Sci USA 1999;96:8235-40.

[115] Gruetter R, Seaquist B, Urgurbil K. A mathematical model of compartmentalized neurotransmitter metabolism in the human brain. Am J Physiol Endocrinol Metab 2001;281:E100-12.

[116] Ugurbil K, Brown TR, den Hollander JA, Glynn P, Shulman RG. High-resolution 13C nuclear magnetic resonance studies of glucose metabolism in Escherichia coli. Proc Natl Acad Sci USA 1978;75: 3742-6.

[117] Bergles DE, Dzubay JA, Jahr CE. Glutamate transporter currents in bergmann glial cells follow the time course of extrasynaptic glutamate. Proc Natl Acad Sci USA 1997;94:14821-5.

[118] Bergles DE, Diamond JS, Jahr CE. Clearance of glutamate inside the synapse and beyond. Curr Opin Neurobiol 1999;9:293-8.

[119] Martinez-Hernandez A, Bell KP, NM D. Glutamine synthetase: glial localization in brain. Science 1976;195:1356-8.

[120] Sibson NR, Dhankhar A, Mason GF, Rothman DL, Behar KL, Shulman RG. Stoichiometric coupling of brain glucose metabolism and glutamatergic neuronal activity. Proc Natl Acad Sci USA 1998; 95:316-21.

[121] Siesjo B. Brain energy metabolism. New York: Wiley, 1978. p. $101-110$.

[122] Fox PT, Raichle ME. Focal physiological uncoupling of cerebral blood flow and oxidative metabolism during somatosensory stimulation in human subjects. Proc Natl Acad Sci USA 1986;83:1140-4.

[123] Duong TQ, Yacoub E, Adriany G, Hu X, Urgurbil K, Vaughan JT, Merkle H, Kim SG. High-resolution, spin-echo BOLD, CBF fMRI at 4 and 7 T. Magn Reson Med 2002;48:589-93.

[124] Lei H, Zhu XH, Zhang XL, Urgurbil K, Chen W. In vivo 31P magnetic resonance spectroscopy of human brain at $7 \mathrm{~T}$ : an initial experience. Magn Reson Med 2003;49:199-205.

[125] Henry P-G, Tkac I, Gruetter R. 1H-localized broadband 13C NMR spectroscopy of the rat brain in vivo at 9.4 Tesla. Magn Reson Med. In press. 